\title{
Chromatin reorganization during myoblast differentiation involves the caspase-dependent removal of SATB2
}

Ryan A.V. Bell1,2*, Mohammad H. Al-Khalaf1,2*, Steve Brunette1, Alphonse Chu1,2, Georg Dechant3, Galina Apostolova3, Jeffrey Dilworth1,2, Lynn A. Megeney1,2\#

1 Regenerative Medicine Program, Sprott Center for Stem Cell Research, Ottawa Hospital Research Institute, The Ottawa Hospital, Ottawa, ON K1H 8L6, Canada

2 Department of Cellular and Molecular Medicine, University of Ottawa, Ottawa, ON, Canada

3 Institute of Neuroscience, Medical University of Innsbruck, Austria

*These authors contributed equally to this work

\#Corresponding author

Lynn A. Megeney

Email: lmegeney@ohri.ca 


\section{Summary}

Induction of lineage-specific gene programs are strongly influenced by alterations in local chromatin architecture. However, key players that impact this genome reorganization remain largely unknown. Here, we report that removal of special AT-rich binding protein 2 (SATB2), a nuclear protein that binds matrix attachment regions, is a key event in initiating myogenic differentiation. Deletion of SATB2 in muscle cell culture models and in vivo, accelerates differentiation and depletes the muscle progenitor pool, respectively. Genome wide analysis indicates that SATB2 binding is both repressive and inductive, as loss of SATB2 leads to expression of differentiation regulatory factors and inhibition of genes that impair this process. Finally, we noted that the differentiationspecific decline in SATB2 protein is dependent on a caspase 7-mediated cleavage event. Taken together, this study demonstrates that temporal control of SATB2 protein is critical for shaping the chromatin environment and coordinating the myogenic differentiation program.

Keywords: SATB2, chromatin remodeling, caspase 7, myogenic differentiation 


\section{Graphical Abstract}

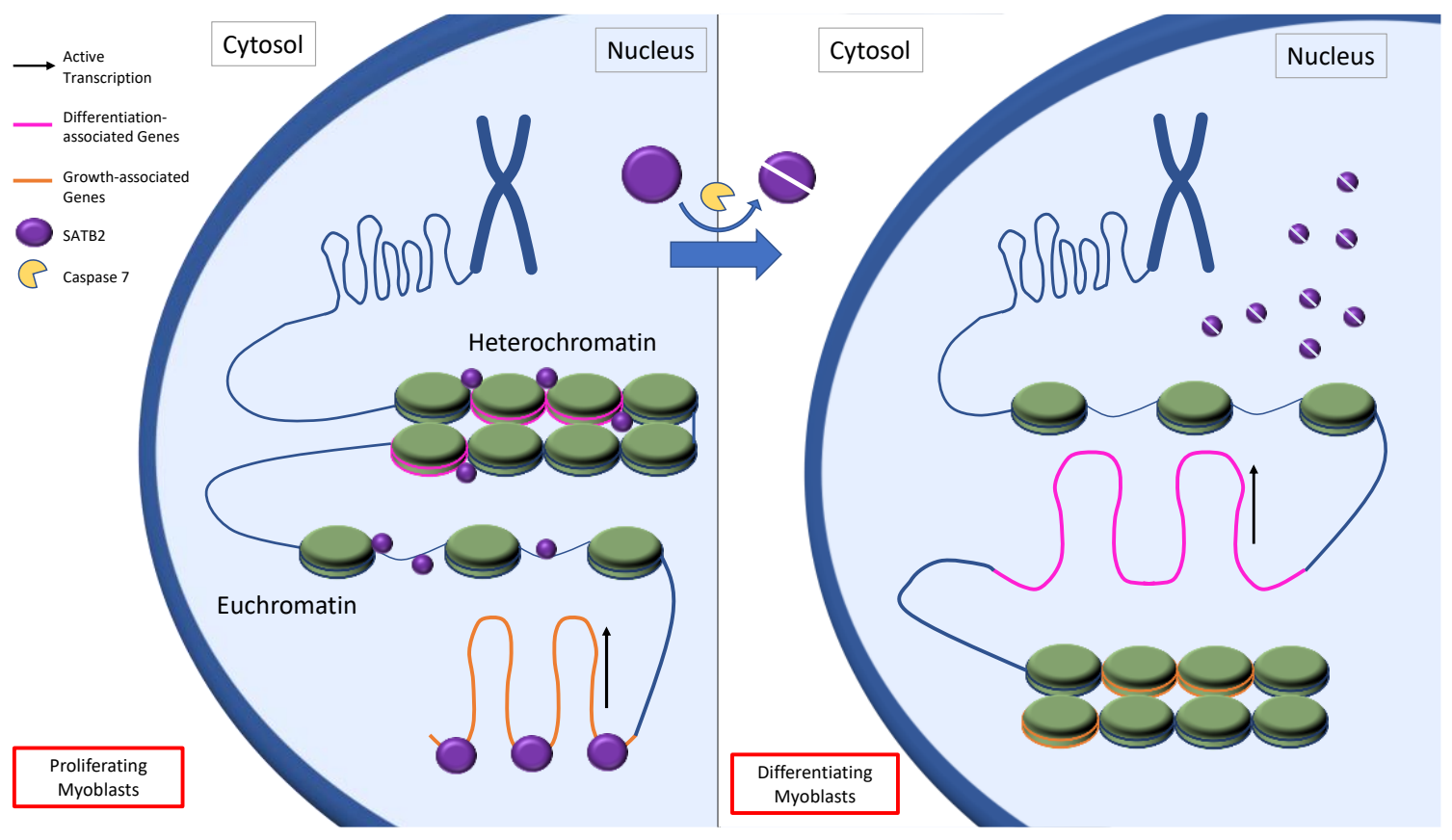




\section{Introduction}

One of the key alterations that characterize a cell's progression through differentiation is a restructuring of the nuclear landscape to allow for the expression of lineage-specific genes. Indeed, chromatin conformation undergoes significant restructuring when cells progress from replicating to differentiating phenotypes, with changes occurring to repress or open access at specific gene loci (Müller and Leutz, 2001; Forcales et al. 2012). These genome alterations are facilitated by two general mechanisms, loci-specific modifications of DNA and histones and targeting of structural proteins that control the higher-order structure of chromatin (Gómez-Díaz and Corces, 2014; Hota and Bruneau, 2016). Progress through the myogenic differentiation program is no exception to this paradigm, with multiple genomic conversions from heterochromatin to euchromatin during myogenesis to allow for muscle-specific genes to be expressed (Doynova et al. 2017). A number of proteins that govern DNA and histone methylation changes have been implicated in the control of myogenesis (reviewed by Robinson and Dilworth, 2018), yet little information exists on the role of proteins that manage higher-order chromatin reorganization during this cell fate determining phase.

The special AT-rich binding proteins (SATB1 and SATB2) are a family of matrix attachment region (MAR) binding proteins that are commonly expressed in stem cells (Savarese et al., 2009; Dong et al., 2015) and play an active role in the global organization of chromatin. MAR binding proteins are unique in that they mediate both repressive and inductive signals for gene expression. This duality of MAR protein function depends on the proximity of gene promoters and insulator regions relative to the position where the MAR protein anchors the DNA to the chromatin scaffold (Bushey et 
al., 2008; Arope et al., 2013). There is increasing evidence that these structural proteins, particularly SATB2, are vital to the epigenetic regulation of numerous genes, several of which are involved in stem cell fate determination and maintaining cancer cell progression (Britanova et al., 2005; Dobreva et al., 2006; Han et al., 2008; Savarese et al., 2009; Dong et al., 2015; Leone et al., 2015). Moreover, human SATB2 mutations are associated with SATB2 syndrome, which is characterized by a plethora of developmental abnormalities, including facial dysmorphia, neural and bone defects, and weak muscle tone in infancy (Bengani et al. 2017). Given these observations, regulation of SATB2 protein content may be a critical step in managing chromatin ultrastructure and gene expression during cell maturation in general.

There is no information regarding how SATB2 manages such a diverse biologic response, nor how SATB2 protein is directed to or removed from its associated genomic targets. However, caspase-mediated cleavage of SATB1 has been shown to be an important step in the control of gene expression that proceeds T-cell apoptosis, where cleavage of SATB1 results in its release from MARs (Galande et al. 2001). Interestingly, caspase proteases have prominent roles in non-death processes such as differentiation, inflammation, remodeling, and cell survival (Unsain and Parker, 2015). The role of caspases in differentiation is particularly well established, with both initiator and executioner caspases being involved in the development of a variety of tissues (reviewed in Bell and Megeney, 2017). With respect to skeletal muscle differentiation, catalytically active caspase 3 and 9 appear to be required for progenitor progression through the myogenic program (Fernando et al. 2002; Murray et al., 2008; Larsen et al. 2010). 
The integral nature of caspase activity during myoblast differentiation and the possibility that caspases could act on chromatin organizing proteins, led us to investigate the behavior of SATB2 within muscle progenitor cells and the potential that caspase enzymes mediate its function.

\section{Results}

\section{SATB2 restrains induction of muscle cell differentiation}

Western blot and immunofluorescent analyses identified SATB2 as a nuclear protein within proliferating $\mathrm{C} 2 \mathrm{C} 12$ muscle cells, which was markedly reduced in expression during the early stages of differentiation (Figure 1A and B). When expressed, SATB2 was mainly relegated to the euchromatic nuclear space, however there was a subfraction of SATB2 co-staining with heterochromatin protein 1 alpha (HP1 $\alpha)$ occurring in the more condensed regions of the nucleus (Figure 1C). Having established that SATB2 protein is reduced during myogenesis, we next sought to determine the role of SATB2 in muscle cell proliferation and differentiation. To this end, we initially designed CRISPR-Cas9 guide RNAs to inhibit SATB2 gene expression in replicating myoblasts. However, infection of C2C12 muscle cells with an adenovirus expressing enhanced Cas9 (Slaymaker et al., 2016) led to a dramatic increase in SATB2 protein content in postdifferentiated myoblasts, at a time when SATB2 would otherwise be in significant decline (see Supplementary Figure 1). Given this unexpected impact of Cas9 on our protein of interest we chose to pursue short interfering RNA (siRNA)-mediated targeting of SATB2 as a means to address its biologic role in cell culture models. siRNA targeting of SATB2 (siSATB2) did not produce any noticeable alteration in cell viability or growth (Supplementary Figure 2). However, siSATB2-treated cells displayed enhanced 
differentiation kinetics (Figure 1D) resulting in a marked increase in myosin heavy chain (MHC) expression at the time points tested compared to cells treated with scrambled siRNA (siControl) (Figure 1E). Moreover, the formation of multinucleated myotubes was dramatically accelerated in SATB2 targeted cells compared to the control condition (Figure 1F). These results indicate that SATB2 plays an important role in mediating the transition from proliferation to induction of the myogenic differentiation program. In vivo depletion of SATB2 in muscle satellite cells decreases muscle fiber area and the number of Pax7-expressing satellite cells

To examine whether loss of SATB2 would alter the muscle cell differentiation program in vivo, we generated satellite cell-specific deletion of SATB2, under the control of tamoxifen induction, by crossing the Satb2flfl mouse strain (Jaitner et al., 2016) with the Pax7CreER mouse strain (Nishijo et al., 2009) to generate Pax7CreER/Satb2flfl mice. Pax7CreER/Satb2flfl mice (and requisite controls, Satb2flfl strain) were given tamoxifen at three weeks of age and monitored continuously (as per University of Ottawa Animal Care and Veterinary Service (ACVS) guidelines). Gross assessment of motor function and physical state indicated that there were no substantial motor effects stemming from the depletion of SATB2. Quantitative assessment of mice weights showed no significant differences between control and Pax7CreER/Satb2flfl mice (data not shown). However, histologic/morphologic analysis revealed notable alterations in skeletal muscle structure between control and Pax7CreER/Satb2flfl mice. For example, measurement of fiber area within the tibialis anterior (TA) from control and Pax7CreER/Satb2flfl mice indicated that the removal of SATB2 from muscle satellite cells led to a significant decrease in fiber area concurrent to an increase in fiber number as compared to the control strains (Figure 
2A-C). Moreover, following tamoxifen treatment, the number of Pax7-expressing satellite cells within Pax7CreER/Satb2flfl TA muscle decreased substantially when compared to the Satb2flfl control muscle (Figure 2D). Collectively, these observations are consistent with the hypothesis that loss of SATB2 in the satellite cell niche leads to premature activation and differentiation of these muscle progenitor cells, which is reflected at the anatomical level by increased numbers of smaller muscle fibers. Chromatin immunoprecipitation (ChIP)- and RNA-seq data support a role for SATB2 in regulating muscle satellite cell differentiation

In order to more clearly identify the genes bound and regulated by SATB2 during muscle cell differentiation, we performed both ChIP- and RNA-seq analyses. Our ChIPseq data was subjected to Gene Ontology categorization using the GREAT software (McLean et al., 2010), which indicated that of the SATB2 binding peaks identified, $91.5 \%$ of the reads mapped to the genome (Figure $3 \mathrm{~A})$. This analysis revealed that SATB2 bound to a large proportion of the mouse genome, covering $38 \%$ of known classified genes (Figure 3B). Unsurprisingly, given that SATB2 is recognized as a structural DNA binding protein, SATB2 was found to bind to many genetic loci in proliferating $\mathrm{C} 2 \mathrm{C} 12$ cells. The binding targets spanned a variety of biological processes (Figure 3C and Supplementary Table 1), with SATB2 bound most frequently to genes associated with chromatin or chromosome organization and cell division. This genome targeting behavior of SATB2 is consistent with the observations in Figures 1 and 2, suggesting that SATB2 may control gene expression during muscle cell proliferation and/or the transition of myoblasts from growth to differentiation. 
To characterize the impact of SATB2 on gene expression during early myoblast differentiation, we performed RNA-seq on siControl- and siSATB2-treated cells that had been differentiated for $24 \mathrm{~h}$. Prior to the analysis of our RNA-seq dataset, we confirmed that siSATB2 was able to significantly reduce $S a t b 2$ expression (Supplementary Figure 3). Assessment of the RNA expression profiles using CuffDiff2 (Trapnell et al. 2013) indicated that 2021 genes were significantly altered in the Satb2-depleted samples as compared to the control samples (Figure 3D and E). Of these genes, 942 were upregulated and 1085 were downregulated following the decrease in Satb2 expression (Figure 3D). Three hundred and twelve of these genes had been previously identified in our ChIP-seq data set (Figure 3E), indicating a particular set of genes that was directly regulated by SATB2 binding. Of those 312 genes, approximately half (148) were upregulated while the other half was downregulated (Figure 3E). Figure 3F shows a subset of the genes identified by RNA-seq and ChIP-seq that indicate the potential role of SATB2 in regulating cell proliferation and differentiation pathways. For example, several of the targets with reduced expression include genes known to repress differentiation, such as Hdac9, Ncoal, Hdgfrp3, Rnf128, and Celf1, whereas a large number of targets with enhanced expression are proteins known to accelerate differentiation, including Smarca4, Wnt9a, Kat2b, Med21, Cdk8, and Bdnf. This heterogenous binding and gene regulation activity of SATB2 is consistent with the euchromatin and heterochromatin distribution during growth and early stages of muscle cell differentiation, suggesting that SATB2 can promote and repress gene expression depending on the loci it targets.

Caspase 7 cleaves SATB2 during early myogenesis 
The mechanisms that govern chromatin remodeling during cellular differentiation remain largely unknown, but evidence from apoptotic nuclei suggests that nuclear structural proteins are targeted by caspase proteases (Galande et al., 2001; Sun et al., 2006; Dudek et al., 2018). Moreover, our identification that a major C-terminal fragment of SATB2 becomes more prominent during muscle cell differentiation suggests that a proteolytic event may target the SATB2 protein (Figure 1A and Supplementary Figure 4). Prior studies from our laboratory have shown that caspase 3 plays a prominent role in myogenesis, targeting and cleaving a number of substrate proteins to engage the differentiation program (Fernando et al. 2002; Larsen et al. 2010; Dick et al. 2015). To examine whether SATB2 proteolysis occurred, we suppressed endogenous effector caspase activity (caspase 3 and 7) with the peptide inhibitor z.DEVD.fmk and reassessed SATB2 protein expression during muscle cell differentiation. Caspase inhibition during differentiation led to sustained expression of SATB2 protein in the nucleus compared to control cells (Figure 4A and B). In an attempt to attribute SATB2 cleavage to either caspase 3 or 7 (or both), an in vitro cleavage assay was performed. This assay demonstrated that caspase 7 activity was very robust at targeting SATB2 protein, whereas caspase 3 did not induce measurable cleavage (Figure 4C). Mass spectrometry analysis of the caspase 7 mediated SATB2 fragments mapped a putative caspase cleavage site at D477 (Supplementary Figures 4 and 5).

To corroborate caspase 7 as a targeting protease of SATB2 and by inference as a regulatory enzyme that may promote muscle cell differentiation, we utilized siRNA to suppress caspase 7 expression. siRNA repression of caspase 7 (siCasp7) led to a concomitant accumulation of SATB2 protein during C2C12 muscle cell differentiation 
when compared to siControl-treated cells (Figure 4D and E). Investigating caspase 7

more closely, we determined that the expression of nuclear, active caspase 7 was inversely correlated with SATB2 expression, with nuclear caspase 7 levels increasing during early myoblast differentiation (Figure 4F). To assess the broad effect of this protease on muscle differentiation, we compared siCasp7 cells (where siRNA treatment reduced caspase 7 expression by $\sim 60 \%$; Supplementary Figure 6) vs. siControl-treated cells and noted that siCasp7 cultures displayed a significant impairment in low serum induction of differentiation, with a dramatic reduction in the expression of $\mathrm{MHC}$ and a near complete inhibition of multi-nucleate myotube formation (Figure 4G). Taken together, these results suggest that a signaling pathway engages caspase 7 activation to target SATB2 protein and that this intersection between a protease and MAR proteins is a critical determinant in securing the muscle cell differentiation program.

\section{Discussion}

Chromatin remodeling plays a central role in stem cell differentiation, as it facilitates the dramatic shift in gene expression profiles that accompanies the exit from the cell cycle and the commitment to a particular lineage (Müller and Leutz, 2001; de la Serna et al. 2006, Keenen and de la Serna, 2008; Fisher and Fisher, 2011; Chen and Dent 2014; Dixon et al. 2015; Hota and Bruneau 2016; Ye et al., 2017). These changes are dependent upon both transcription mediated change concurrent with a shift in the epigenetic landscape, which may allow or limit gene expression in the relevant regions of the genome. One mechanism that will influence lineage-dependent transcription and epigenetic change is the presence (or absence) of higher order MAR proteins that mediate chromatin structure, and thereby physical access to key genetic loci (Hawkins et al., 
2001; Savarese et al., 2009; Asanoma et al., 2012). While changes to the chromatin architecture within skeletal muscle progenitor cells have been observed (Doynova et al. 2017), the exact players that govern these changes are not well known. Here, we identified SATB2 as a chromatin organizer that plays a key role in mediating the progression of myoblasts into the myogenic differentiation program.

Interestingly, reduction of SATB2 expression did not affect myoblast proliferation (Supplementary Figure 2), indicating that SATB2 may primarily block cells from prematurely entering into a terminally differentiated state by denying access to important myogenic genes. Reduced expression of SATB2 during early myogenesis appears to accelerate the differentiated phenotype, as evidenced by the siRNA-mediated knockdown of SATB2, which hastens the expression of MHC (Figure 1E) and accelerates the formation of myotubes during early differentiation (Figure 1F). This coincides with our supposition that SATB2 may sequester myogenic genes (perhaps within the heterochromatic areas of the nucleus), and once removed, primes myoblasts for myogenic gene expression.

As noted above, SATB2 protein within muscle cells is mainly relegated to euchromatic regions of the nucleus, with a reduced but defined sub-localization of the protein in heterochromatic areas (Figure 1C). This localization pattern is evident during growth conditions and is consistent with the concept that SATB2 promotes cell proliferation through its action on genetic loci in euchromatin regions. The corollary to this is the impact on SATB2 targeted loci during differentiation, where SATB2 is removed from the nucleus, which simultaneously represses growth-related euchromatic genes and relieves repression of differentiation-specific genes that were previously 
sequestered in the heterochomatic regions of the nucleus. This hypothesis is supported by the ChIP- and RNA-seq data where a number of genes that are potent promoters of cell proliferation were downregulated during early myoblast differentiation, including $H d a c 9$ (Lapierre et al. 2016), Celfl (Xia et al., 2015), Ncoal (Wang et al., 2018), Hdgfrp3 (Xiao et al., 2013), and $\operatorname{Rnf128}$ (Lee et al., 2016), all of which were significantly downregulated following SATB2 removal during early stages of the differentiation program (Figure 3F). Conversely, we identified several differentiation-specific genes that showed an increase in expression following SATB2 depletion during early myogenesis. This list includes Smarca4, which is known to play a role in neurogenesis (Yu et al., 2013), erythropoiesis (Griffin et al., 2008), and myogenesis (Albini et al., 2015); Wnt9a, which is a positive regulatory factor in hematopoiesis (Richter et al., 2018) and mediates the transition from proliferation to differentiation in skeletal myoblasts (Tanaka et al., 2011). Furthermore, $C d k 8$ was upregulated following the loss of SATB2 protein during early muscle differentiation, and is known to be important for mediating Notch degradation, which is critical for satellite cells to exit the cell cycle and enter the myogenic differentiation program (Buas and Kadesch, 2010). These findings support the premise that SATB2 in proliferating myoblasts acts to maintain cell proliferation, while the induction of differentiation leads to the loss of SATB2 and the repression of growth-associated genes and the activation of previously sequestered differentiation-associated gene program.

Caspase signaling is an inductive cue for skeletal muscle differentiation and a number of caspase 3 substrates have been identified which participate in the differentiation process. These proteins include the mammalian sterile twenty-like kinase, MST1, which when cleaved by caspase 3 engages a self-contained promyogenic signal 
(Fernando et al., 2002). Caspase 3 can also moderate earlier steps in the myogenic cascade by targeting proteins the promote stem cell self renewal such as Pax7 (Dick et al. 2015). Caspase 3 also engages a regulated form of DNA damage and repair, which acts a prodifferentiaon signal (Larsen et al. 2010; Al-Khalaf et al 2016). Here, caspase 3 engages activation of CAD by cleaving and removing its cognate inhibitor protein ICAD. Once activated CAD targets regions of the genome, inflicting strand breaks which activate expression of $\mathrm{p} 21$, a conserved cell cycle inhibitor that governs differentiation across multiple cell lineages (Larsen et al. 2010).

Despite the prominent role of caspase 3 in the differentiation process, we have noted that SATB2 is cleaved exclusively by the effector caspase, caspase 7. Cytosolic caspase 7 activity has been suggested to promote odontogenesis (Matalova et al. 2013; Svandova et al. 2018), yet nuclear caspase 7 disposition is considered to be an exclusive hallmark of apoptosis (Zhivotovsky et al. 1999; Kamada et al. 2005). For example, remodeling the chromatin micro-environment through targeted protein cleavage events is considered to be a conserved feature of apoptosis, as exemplified by effector caspase cleavage of scaffold attachment factor b1 (Lee et al., 2007), lamina-associated polypeptide $2 \alpha$ (Gotzmann et al., 2000), and SMARCA2 and SMARCA4 (Dudek et al., 2018). Nevertheless, our observations support a novel model whereby an effector caspase, caspase 7 , targets a protein substrate (SATB2) to prime the nuclear matrix to engage differentiation, independent of cell death.

Presumably, during muscle cell differentiation the activation of caspase 7 is mediated by the same pathway that leads to the induction of caspase 3 , via engagement of the mitochondrial intrinsic cell death pathway (Murry et al. 2008). The pattern of caspase 
7 activation is remarkably similar to caspase 3 in differentiating myoblasts, which does support a common signaling origin. What is more speculative is whether a level of integration may exist between caspase 3 and caspase 7 activity, where targeting of their respective substrates is coordinated to drive the same biologic alteration. Given that SATB2 is a MAR protein, it is not unreasonable to suggest that caspase 7 cleavage of this protein may provide accessibility for CAD to target the genome and induce the requisite strand breaks during early stages of the differentiation program. Indeed, CAD does not target a specific DNA sequence, which suggests that the nuclease gains access to its genomic targets through an undefined structural change (Larsen and Sørenesen, 2017). However, our ChIP-seq analysis indicated that SATB2 was not enriched at a well-defined CAD target, the p21 promoter, and follow on ChIP PCR experiments validated this observation (Supplemental Figure 7). While this single observation does not preclude SATB2 shielding other undefined CAD targets, it does indicate that SATB2 and CAD have distinct genome reorganizing roles during muscle cell differentiation. As such, we favour the hypothesis that caspase 7 targeting of SATB2 is a temporally linked yet distinct biochemical step caspase mediated control of myogenesis. Finally, it is germaine to note that SATB2 is widely expressed and caspase signaling is an inductive cue for differentiation across multiple cell lineages and phyla. This convergence raises the possibility that caspase 7 cleavage of SATB2 may be a conserved mechanism to reprogram the nuclear architecture for cell differentiation. 


\section{Acknowledgements}

The authors would like to thank members of the Megeney laboratory and Michael

Rudnicki for helpful discussion. We would also like to thank Lawrence Puente for the mass spectrometry analysis (Proteomics Core Facility, Ottawa Hospital Research

Institute). This work was supported by grants from the Canadian Institutes of Health

Research (L.A.M. and J.D.).

\section{Author Contributions}

Conceptualization: L.A.M., J.D., G.D., and G.A. Formal analysis: R.A.V.B., M.H.A., and A.C. Investigation: R.A.V.B., M.H.A., and S.B. Writing - Original Draft: R.A.V.B. and M.H.A. Writing - Review and Editing: R.A.V.B., M.H.A., and L.A.M. Visualization: R.A.V.B. and M.H.A. Supervision: L.A.M. and J.D. Funding Acquisition: L.A.M.

\section{Declaration of Interests}

The authors declare no competing interests. 


\section{Figure Captions}

Figure 1. SATB2 regulates myogenic gene expression during myoblast differentiation.

(A) Representative western blot showing the decreased expression of full-length SATB2

(FL-SATB2) during a differentiation time course for C2C12 cells. This was accompanied by a concomitant increase in a C-terminal fragment of SATB2 (C-Term SATB2). (B)

Representative immunofluorescent staining of SATB2 in proliferating and differentiated $\mathrm{C} 2 \mathrm{C} 12$ cells. Images are representative of $\mathrm{n}=5$ independent samples at each time point. DAPI (blue), SATB2 (red); scale $=10 \mu \mathrm{M}$. (C) Representative immunofluorescent images depicting SATB2 localization in relation to heterochromatin protein $1 \alpha(\mathrm{HP} 1 \alpha)$. Images are representative from $n=3$ independent determinations for each time point. Scale bar $=10 \mu \mathrm{M}$. DAPI (blue), SATB2 (red), HP1 $\alpha$ (teal). (D) Immunofluorescent images depicting the efficacy of SATB2 depletion using siRNA. Muscle cell cytoplasm was counterstained with an anti-GAPDH antibody. Images are representative of $n=3$ independent determinations. DAPI (blue), GAPDH (green), and SATB2 (red). Scale bar for the low magnification column $=10 \mu \mathrm{M}$. Scale bar for the higher magnification column $=5 \mu \mathrm{M}$. (E) Western blot showing the myosin heavy chain (MHC) protein expression during growth and differentiation time points following siControl or siSATB2 treatments in $\mathrm{C} 2 \mathrm{C} 12$ cells. Image is representative of $\mathrm{n}=3$ independent determinations. GAPDH was used as a loading control. (F) Immunofluorescent images indicating that the depletion of SATB2 leads to early myotube formation after C2C12 cells were induced to differentiate. Images are representative of $n=3$ independent determinations. DAPI (blue), SATB2 (red), and desmin (green). Scale bar $=50 \mu \mathrm{M}$. 
Figure 2. In vivo reduction of SATB2 in muscle satellite cells decreases muscle fiber area and the number of Pax7-expressing satellite cells. (A) Tibialis anterior fiber areas decreased in Pax7CreER/Satb2flffl mice as compared to control (Satb2flfl) mice. ImageJ was used to the measure the fiber areas of hematoxylin and eosin $(\mathrm{H} \& \mathrm{E})$ stained tissue sections. Data are the means $\pm \mathrm{SEM}, \mathrm{n}=3$ independent determinations on separate tissue samples. H\&E stained sections are representative of $n=3$ independent determinations. Scale bar: $100 \mu \mathrm{M}$. (B) The distribution of muscle fiber sizes across 15 bins. Over 200 muscle fibers were measured for both control and Pax7CreER/Satb2flfl mice. (C) Bar graph indicating the significant increase in the relative number of muscle fibers per $\mu \mathrm{M}_{2}$. Data are the means \pm SEM, $\mathrm{n}=3$ independent determinations on separate tissue samples. (D) The percentage of nuclei that were Pax7-positive in control (Satb2 fl) and Satb2ablated (Pax7CreER Satb2 fl) mouse muscle. The panels below the bar graph are representative tissue sections stained with a Pax7 antibody (Pax7) or no antibody (Control); scale: $50 \mu \mathrm{M}$. Arrows indicate positively stained nuclei. Data are representative of $\mathrm{n}=3$ independent determinations on separate tissue samples. * indicates a significant difference between Pax7CreER/Satb2flfl and Satb2flfl mice as determined by the Student's $t$-test $(\mathrm{p}<0.05)$.

Figure 3. SATB2 regulates the expression of many genes associated with various biological processes within myoblasts. (A) GREAT-input identified $8413(91.5 \%)$ of the 9010 peaks generated from SATB2 ChIP-sequencing; (B) identified peaks corresponded to $38 \%$ of the 21902 Mus musculus genes classified in the UCSC mm10 NCBI build 38 species assembly. (C) Pie chart shows the distribution of the genes identified as it relates to Gene Ontology (GO) category clusters shown in Supplementary Table S1. (D) Cuffdiff 
analysis of the RNA-seq dataset show that 2027 genes were identified to have significantly altered expression between the control and knockdown conditions, with 1085 genes being significantly downregulated in expression and 942 genes being significantly upregulated. (E) Venn diagram comparing MACS-identified SATB2 ChIPseq genes (4001) from C2C12 cells under growth conditions with Cuffdiff-identified SATB2 knockdown RNA-seq genes (2021) from 24 h-differentiated cells. Three hundred and twelve genes were found to be bound to SATB2 in proliferating cells, which was altered significantly following the reduction in Satb2 gene expression. Of those 312 genes, 164 were significantly downregulated and 148 were significantly upregulated. (F) Graph highlights a selection from the 312 genes identified in common between the ChIPseq and RNAseq datasets. These selected genes (19 upregulated and 19 downregulated) are all known to be involved in the genetic switch from a proliferative program to a differentiation program. The RNA-seq dataset is the result of the analysis of $n=3$ independent determinations.

Figure 4. Caspase 7 cleaves SATB2 during early skeletal muscle differentiation and is necessary for myogenesis. (A) Immunofluorescent staining of SATB2 following caspase inhibition by z-DEVD.fmk (DEVD) in proliferating and differentiating C2C12 cells. Images are representative of $\mathrm{n}=3$ determinations on independent samples. DAPI (blue); SATB2 (red); scale: $10 \mu \mathrm{M}$. (B) Quantification of SATB2 nuclear expression following DEVD-mediated suppression of caspase activity. Data are the means \pm SEM from $n=3$ independent samples; 75-100 cells per condition/time point were analyzed. ** indicates $\mathrm{p}$ $<0.01$ and $* * *$ indicates $\mathrm{p}<0.001$ as determined by the Student's $t$-test. (C) Silver stained gel of an in vitro caspase cleavage assay. Reactions included combinations of 
recombinant SATB2 protein, active caspase 3/7 recombinant proteins, caspase chemical inhibitor (DEVD), or the control chemical DMSO. (D) Caspase 7 and SATB2 expression following siCasp7 and siControl treatments of C2C12 cells. Both the histogram and the representative western blots $(n=3)$ were the expression levels of those two proteins $48 \mathrm{~h}$ post-induction of differentiation. * indicates a significant difference in caspase 7 or SATB2 expression as determined by the Student's $t$-test $(\mathrm{p}<0.05)(\mathrm{E})$ Immunofluorescent images showing the sustained expression of SATB2 after the depletion of caspase 7 in $\mathrm{C} 2 \mathrm{C} 12$ cells differentiated for $48 \mathrm{~h}$. Images are representative of $\mathrm{n}=3$ independent determinations. (F) Representative western blot depicting the cleaved active fragment of caspase 7 found in the nuclear fraction of $\mathrm{C} 2 \mathrm{C} 12$ cells during their proliferative phase (Gr) and at various stages of differentiation (6-72 h post-induction; $\mathrm{n}$ = 3). Staurosporine (STS) was used as a positive control. (G) Representative western blot showing the reduction in caspase expression in differentiating $\mathrm{C} 2 \mathrm{C} 12$ myoblasts $(48 \mathrm{~h}$ post-induction; $n=3$ ). See the Supplemental Information for the quantification of the knockdown of caspase 7 (Supplemental Figure S6). (E) Immunofluorescent staining of myosin heavy chain (MHC) in siControl- and siCasp7-treated C2C12 myoblasts under growth and differentiation conditions. Panel is representative of $n=3$ determinations on independent samples. DAPI (blue), MHC (green). 


\section{Supplemental Information}

Figure 1. SATB2 expression following adenoviral Cas9 transfection into C2C12 myoblasts. SATB2 expression increased following Cas9-GFP-ad transfection as compared to no transfection and GFP-ad transfection controls (48 h differentiated $\mathrm{C} 2 \mathrm{C} 12$ cells). * indicated the location of the full-length SATB2. Cas9 expression was confirmed in the Cas9-GFP-ad cells and is shown in a panel above the main blot.

Figure 2. siRNA-mediated depletion of SATB2 does not affect C2C12 proliferation and survival. C2C12 cells were counted using bright field microscopic images under low magnification. Each individual cell in a field was marked and counted using ImageJ cell counter software. Data are means \pm SEM for $n=3$ independent determinations. No statistically significant difference in cell number was observed between siControl and siSATB2 treatments at each time point.

Figure 3. Validation of SATB2 downregulation following siSATB2 treatment via RNAseq. The $\mathrm{C} 2 \mathrm{C} 12$ cell samples were from the $24 \mathrm{~h}$ differentiated time point. $* * *$ indicates a significant difference between siControl and siSATB2 samples as determined by the Student's $t$-test $(\mathrm{p}<0.001)$.

Figure 4. Identification of the caspase cleavage site within SATB2. (A) Silver stained gel of an in vitro caspase cleavage assay involving recombinant SATB2 and caspase 7. * indicates the major cleavage fragment that was analyzed by mass spectrometry and 
included the D477 cleavage site. (B) Mass spectrometry analysis of the major cleavage fragment SATB2, identified with an * in (A).

Figure 5. The amino acid sequence of Mus musculus SATB2, with the major cleavage fragment underlined and the caspase cleavage fragment bolded. The red ' $\mathrm{D}$ ' indicates the aspartic acid residue where cleavage occurs.

Figure 6. Relative caspase 7 expression following knockdown with siCasp7 in differentiating C2C12 myoblasts. Data are means $\pm \mathrm{SEM}, \mathrm{n}=3$ independent determinations. * indicates a statistically significant difference versus the siControl condition using the Student's $t$-test, $\mathrm{p}<0.05$.

Figure 7. Enrichment of SATB2 at the $p 21$ locus during C2C12 differentiation. Chromatin immunoprecipitation (ChIP) using an anti-SATB2 antibody indicted that SATB2 was not significantly enriched at the $p 21$ locus during cell proliferation or differentiation. (A) Representative PCR amplification of $p 21$ following ChIP using a SATB2 antibody. The negative control was ChIP using a mouse IgG. (B) Quantification of ChIP PCR results for the $p 21$ locus. 


\section{Supplementary Tables}

Table 1. Top 25 Gene Ontology biological processes identified within the SATB2-ChIPseq dataset.

Table 2. RNA-seq-identified genes that were downregulated following Satb2 depletion in C2C12 cells. The genes shown here were also part of the ChIP-seq dataset.

Table 3. RNA-seq-identified genes that were upregulated following Satb2 depletion in $\mathrm{C} 2 \mathrm{C} 12$ cells. The genes shown here were also part of the ChIP-seq dataset. 


\section{Materials and Methods}

Mice and in vivo procedures

All mice were housed and treated at the University of Ottawa Animal Care and Veterinary Services. Mice used in our studies were housed and cared for according to Canadian Council on Animal Care (CCAC) guidelines and University of Ottawa Animal Care Committee protocols.

In order to determine the effects of SATB2 removal from muscle satellite cells, Pax7/CreER Satb2flfl and Satb2fl/fl (control) mice were fed a diet supplemented with tamoxifen (40 mg/kg body weight; Envigo) at 3 weeks old. These mice were monitored weekly for evidence of potential effects of SATB2 ablation from muscle stem cells. After 8-10 months, three Pax7/CreER Satb2flfl and Satb2flfl mice (female) were euthanized by $\mathrm{CO}_{2}$ asphyxiation and cervical dislocation. These mice were then assessed for any structural abnormalities, and their tibialis anterior muscle was excised and fixed in $10 \%$ neutral buffered formalin. After $24 \mathrm{~h}$, the samples were then placed in $70 \%$ ethanol and then paraffin embedded and cut into $4 \mu \mathrm{m}$ sections. To determine muscle fiber areas, sections were stained with hematoxylin and eosin $(\mathrm{H} \& \mathrm{E})$ and assessed under an Observer A1 microscope (Zeiss). Muscle fiber area was determined using the ImageJ software. To investigate the percentage of Pax7-expressing satellite cells, sections were stained with a Pax7 antibody, as well as just the secondary antibody as a control.

\section{Cell culture}

Cells of the immortalized mouse cell line, $\mathrm{C} 2 \mathrm{C} 12$, were grown on non-collagen coated cell culture plates in Dulbecco's Modified Eagle's medium (DMEM) with 10\% fetal bovine serum (FBS) and 1\% penicillin/streptomycin (growth medium). When 
confluent, cells were differentiated in DMEM supplemented with 2\% horse serum and $1 \%$ penicillin/streptomycin (differentiation medium).

\section{Protein extraction and western blotting}

C2C12 cells were lysed using a modified RIPA buffer (50 mM Tris-HCl, $\mathrm{pH} 7.4$, $150 \mathrm{mM} \mathrm{NaCl}, 1 \mathrm{mM}$ ethylenediaminetetraacetic acid (EDTA), 1\% NP-40, $1 \%$ glycerol, and a cocktail of protease inhibitors) for whole cell extracts, or a modified NE-PER Nuclear and Cytoplasmic Extraction Kit, as per the manufacturer's instructions (Thermo Scientific). Extracted proteins were then separated via SDS-PAGE and then transferred to a $0.45 \mu \mathrm{M}$ polyvinylidene fluoride (PVDF) membrane (Millipore) on a TRANS-BLOT SD apparatus (Bio-Rad). Membranes were blocked with Tris-buffered saline plus $0.1 \%$ Tween-20 (TBST) containing 5\% skim milk for $1 \mathrm{~h}$ at room temperature. Membranes were then incubated overnight at $4{ }^{\circ} \mathrm{C}$ with primary antibody made in blocking solution. The primary antibodies used in this study included mouse SATB2 (ab51502; Abcam; 1:1000), rabbit caspase 7 (9491S; Cell Signaling; 1:1000), mouse myosin heavy chain (DSHB; MHC; 1:250), and mouse glyceraldehyde 3-phosphate dehydrogenase (\#2118; GAPDH; 1:4000).

\section{Immunofluorescence}

C2C12 cells were cultured and fixed in paraformaldehyde on $25 \mathrm{~mm}$ coverslips at the desired time points. The cells were then incubated for $10 \mathrm{~min}$ at room temperature with a permeabilization solution containing $0.5 \%$ Triton-X 100 in PBS. Subsequently, the cells were incubated for $1 \mathrm{~h}$ with a blocking solution consisting of $5 \%$ horse serum in PBS. After blocking, the cells were incubated for $2 \mathrm{~h}$ at room temperature or overnight at $4{ }^{\circ} \mathrm{C}$ in primary antibody that was reconstituted in blocking solution. The primary 
antibodies used were mouse SATB2 (1:50; ab51502, Abcam), rabbit HP1 $\alpha$ rabbit (1:200; \#2616, Cell Signaling), rabbit Gapdh (1:400; \#2118, Cell Signaling), rabbit desmin (1:400; ab15200, Abcam), and mouse MHC (1:50; DSHB). After primary antibody incubation, the cells were washed three times in PBS and incubated in secondary antibody (2 mg/mL Alexa Fluor 488, Invitrogen, 1:1500, 2 mg/mL Alexa Fluor 594, Invitrogen, 1:1500; $2 \mathrm{mg} / \mathrm{mL}$ Alexa Fluor 568, Invitrogen, 1:1000) diluted in PBS for 1.5 $\mathrm{h}$ at room temperature. After incubation, the cells were washed $2 \times$ in PBS and then counterstained with 4',6-diamidino-2-phenylindole dihydrochloride (DAPI; 1:10 000; Sigma) for $10 \mathrm{~min}$ at room temperature. After incubation, the cells were washed $2 \times$ in PBS and the coverslips were mounted on microscope slides using Dako Fluorescent Mounting Medium. Cells were then visualized using a Zeiss Observer Z1 inverted fluorescence microscope. All images were developed using AxioVision 4.8 software. The quantification of nuclear SATB2 was performed by densitometry analysis using ImageJ/Photoshop C3 software.

\section{Chromatin immunoprecipitation (ChIP) assay}

Cells were grown on $15 \mathrm{~cm}$ plates and allowed to reach $100 \%$ confluence before either being collected or switching to differentiation media and allowed to incubate until the desired time point was achieved. Twenty million cells per time point were used for each ChIP sample. Cells were fixed for 10 min using $1 \%$ formaldehyde in DMEM. Cell fixation was quenched by removing the fixation solution, rinsing the plates with PBS, and then pouring a solution of $0.125 \mathrm{M}$ glycine in PBS onto the cells and incubating for 5 min. Subsequently, plates were washed $2 \times$ with PBS and then cells were scraped from the plates, pelleted, and stored at $-80{ }^{\circ} \mathrm{C}$ until used. 
Given that SATB2 is a nuclear matrix attachment protein, it required an alternative protocol for chromatin shearing than standard preparations. First, a commercial hypotonic solution (Active Motif) was used to lyse cellular membranes but retain intact nuclear membranes. We subsequently performed additional lysis using a hand held glass Dounce homogenizer. After centrifugation, the supernatant was discarded and the pelleted nuclei were treated with Active Motif's Pro-enzymatic Digestion Nuclear Extraction Solution. After incubation at $37^{\circ} \mathrm{C}$ for $5 \mathrm{~min}$, we supplemented the reaction with $1 \mathrm{U}$ micrococcal nuclease (New England Biolabs) and allowed it to incubate for $10 \mathrm{~min}$. We then supplemented the reaction with SDS to a final volume $2 \%$ SDS-chromatin solution. We proceeded to the second stage of shearing using sonication via a Covaris M220 Focused-Ultrasonicator instrument, setting the parameters to produce sheared DNA of $200 \mathrm{bp}$. After sonication, we performed a final centrifugation at 16000 $\times g$ at $4{ }^{\circ} \mathrm{C}$ for $20 \mathrm{~min}$ and collected the supernatant containing the sheared chromatin.

We performed immunoprecipitations with $5 \mu \mathrm{g} 1^{\circ} \mathrm{Ab}$ (Target: SATB2, Abcam, positive control: RNA pol II, Active Motif, negative control: mouse IgG, Santa Cruz) using magnetic beads (Active Motif) diluted in commercial ChIP-buffer (Active Motif) overnight at $4{ }^{\circ} \mathrm{C}$. Captured chromatin was isolated using magnetic stands to pulldown the beads. Bound DNA was subsequently eluted with commercial elution, reverse crosslinking, protein digestion, and RNA digestion solutions (Active Motif). The resulting samples of DNA were further purified using phenol:chloroform extraction procedures. Final DNA was quantified using a NanoDrop spectrophotometer, with a $25 \mu \mathrm{L}$ final volume having concentrations of $75-100 \mathrm{ng} / \mu \mathrm{L}$.

\section{ChIP-sequencing and bioinformatics}


For genome-wide analysis, immunoprecipitated DNA was amplified and $75 \mathrm{bp}$ single read sequencing was performed on an Illumina HiSeq 2500 at the Next-Generation Sequencing Facility at The Centre for Applied Genomics in The Hospital for Sick Children (Toronto, Ontario, Canada). The data were summarized and basic comparisons performed using the Excel spreadsheet program (Microsoft). Reads were aligned to the NCBI build 38 (UCSC mm10, Dec/2011) genome from the UCSC genome browser using the default options. Data were summarized and basic comparisons performed using MACS version 2.1.0.20140616, and Gene Ontology (GO) term annotation was performed using GREAT v3.0.0 available online from the Bejerano lab at Stanford University (McLean et al, 2010).

RNA-sequencing and bioinformatics

Total RNA was isolated using an RNeasy Kit (QIAGEN) using an on-column DNase digestion (RNase-Free DNase Set, QIAGEN) to avoid genomic DNA contamination. Library preparation and 126-bp paired-end RNA-seq was performed by the Next-Generation Sequencing Facility at The Centre for Applied Genomics in The Hospital for Sick Children. RNA integrity was assessed using the Bioanalyzer platform (Agilent Technologies, Inc.). Sequencing was performed using standard procedures for the Illumina HiSeq 2500 platform. Gene expression quantification was performed using CuffDiff 2 software (Trapnell et al 2013). Data were summarized and basic comparisons were performed using the Excel spreadsheet program (Microsoft).

Caspase cleavage assays

Recombinant SATB2 protein (250-500 ng; Abnova) and recombinant active caspase 3 (0.5 $\mu \mathrm{g}$; Chemicon) or recombinant active caspase 7 (0.5 $\mu \mathrm{g}$; Biovision) were 
incubated for $3 \mathrm{~h}$ in cleavage assay buffer (50 mM Hepes, pH 7.5, $0.1 \mathrm{M} \mathrm{NaCl}, 10 \%$ (v/v) glycerol, $0.1 \%$ Chaps, $10 \mathrm{mM}$ dithiothreitol) containing either dimethyl sulphoxide (DMSO) or z.DEVD.fmk (20 $\mu \mathrm{M}$; BioVision) as indicated. Reactions were stopped by the addition of Laemmli sample buffer, and subjected to sodium dodecyl sulphide polyacrylamide gel electrophoresis (SDS/PAGE). Mass spectrometry was performed at the Ottawa Hospital Research Institute Proteomics Core Facility (Ottawa, Canada). MASCOT 2.3.01 software (Matrix Science) was used to infer peptide and protein identities from the mass spectra.

\section{Caspase inhibition assays}

For caspase 3/7 inhibition, cultured C2C12s were pre-treated with either $15 \mu \mathrm{M} \mathrm{z-}$ DEVD-fmk (DEVD) from BioVision or $15 \mu \mathrm{M}$ DMSO from Sigma for $2 \mathrm{~h}$ at $37^{\circ} \mathrm{C}$. After pre-treatment, the cells were induced to differentiate using low serum media or continued in growth media both containing $15 \mu \mathrm{M}$ DEVD or DMSO as a vehicle-only control. The inhibition or control media was changed every $48 \mathrm{~h}$ until the end of the time course. Cells were collected at the predetermined time points and analyzed as described. siRNA-mediated depletion of SATB2 and caspase 7 gene expression

siRNA duplexes were used to suppress SATB2 and caspase 7 gene expression in C2C12 cells. C2C12 cells were transfected at $25 \%$ confluence with $10 \mathrm{nM}$ siRNA (siSATB2, siCasp7, or siControl) and the Lipofectamine RNAiMAX reagent, as directed by the manufacturer's protocol (Invitrogen). After an overnight incubation, fresh media was added onto the cells and the cells were re-transfected. This continued until the cells reached $100 \%$ confluence, after which differentiation media was added to the cells. Media change and re-transfection occurred every $24 \mathrm{~h}$ throughout the indicated time 
course. Cells were collected or used in subsequent experiments at a growth time point and $24,48,72$, and $96 \mathrm{~h}$ of differentiation.

Statistical Analysis

Statistical analysis of three or more data sets was performed using one-way analysis of variance (ANOVA). For comparison between two sample sets, an unpaired, 2tailed Student's $t$-test was performed. $\mathrm{p}<0.05$ was considered statistically significant. 
Figure 1.

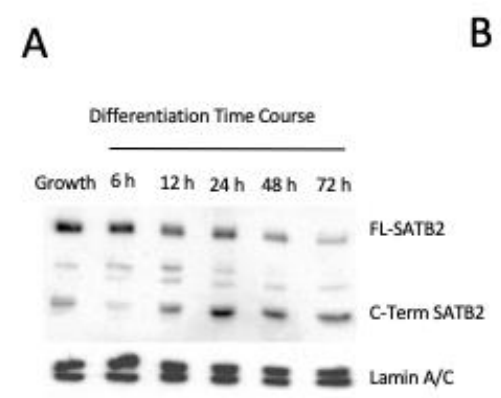

B

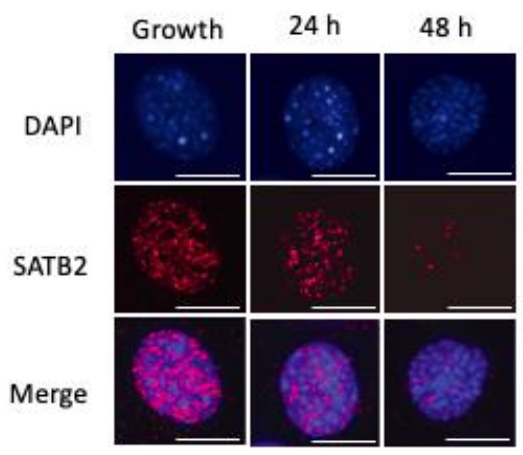

C

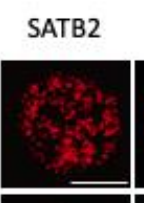

$24 \mathrm{~h}$

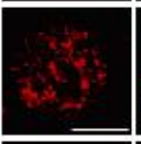

$48 \mathrm{~h}$

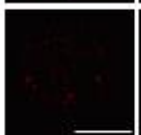

DAPI Merge

\begin{tabular}{|c|c|}
\hline 3 & $\frac{1}{25}$ \\
\hline 4 & wit \\
\hline & 758 \\
\hline
\end{tabular}

D

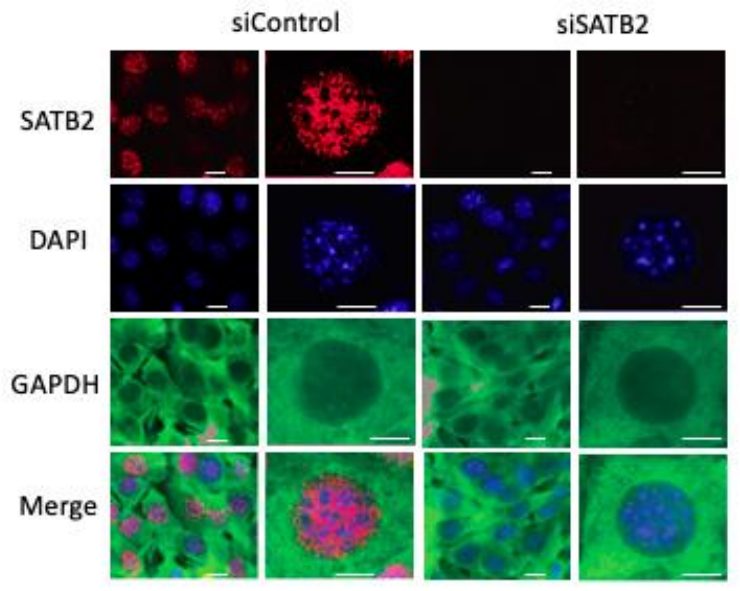

E
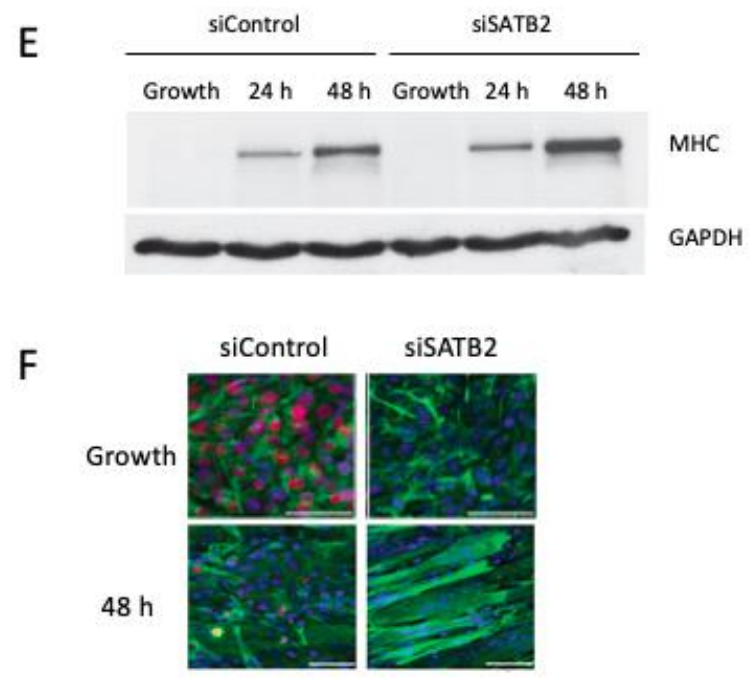
Figure 2

A

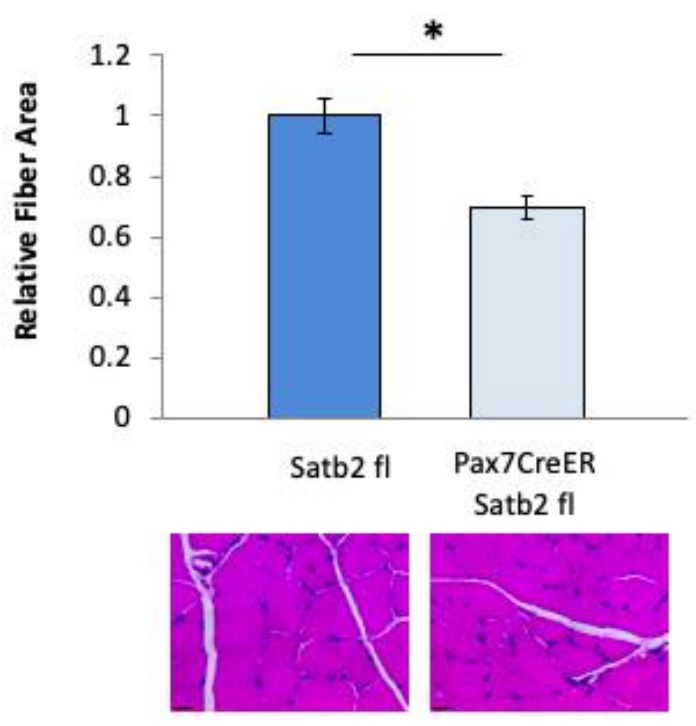

C

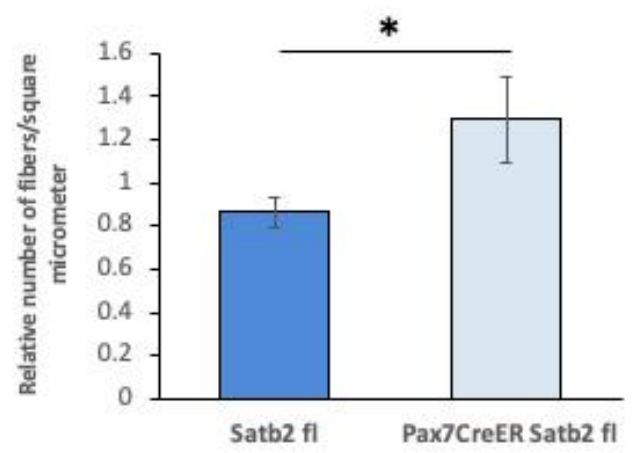

B

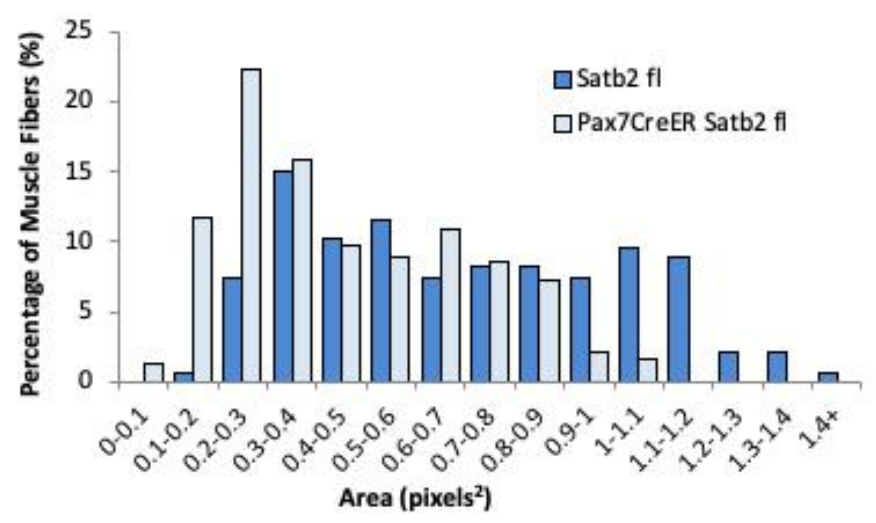

D
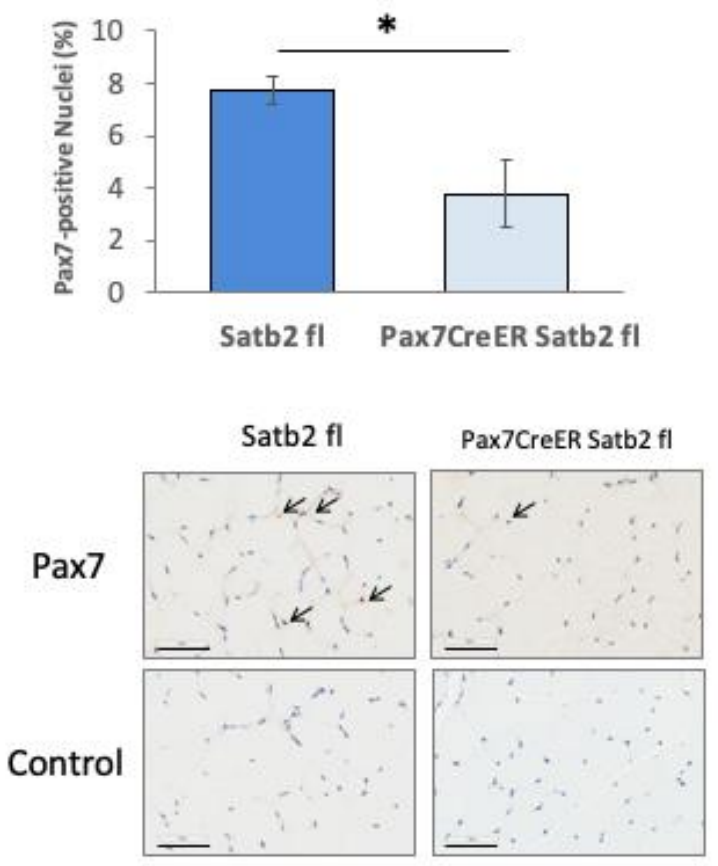
bioRxiv preprint doi: https://doi.org/10.1101/2019.12.19.883579; this version posted December 20, 2019. The copyright holder for this preprint (which was not certified by peer review) is the author/funder. All rights reserved. No reuse allowed without permission.

Figure 3 .

A

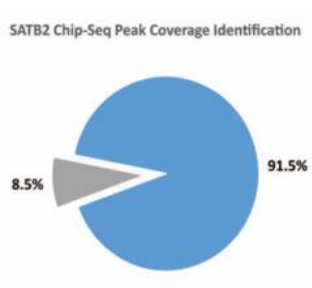

- Identified peaks = Unidentified peaks

B

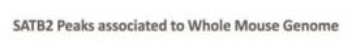

$62 \%$

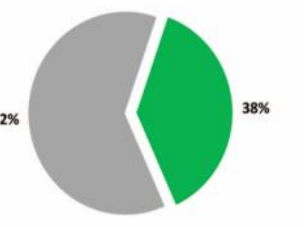

- SATB2 associated = SATB2 unassociated
C

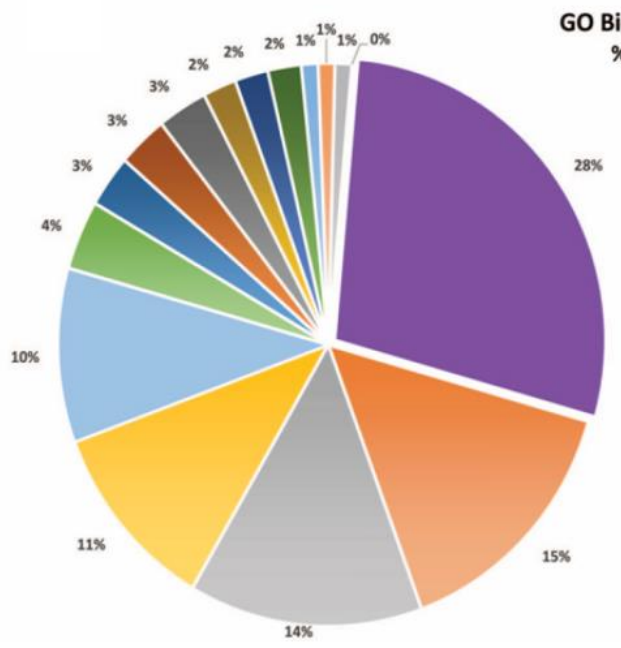

GO Biological Category Distribution

$\%$ number of genes identified

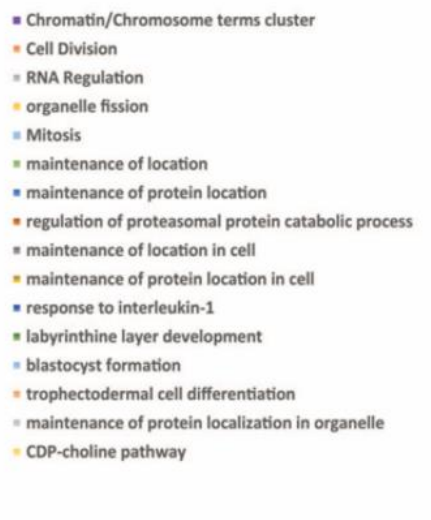

- Chromatin/Chromosome terms cluster

in catabolic process

- maintenance of protein location in cell

maintenance of protein localization in organelle
E

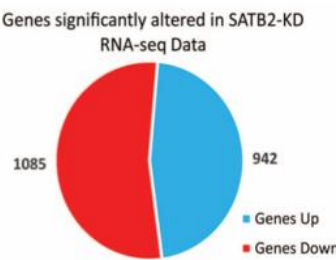

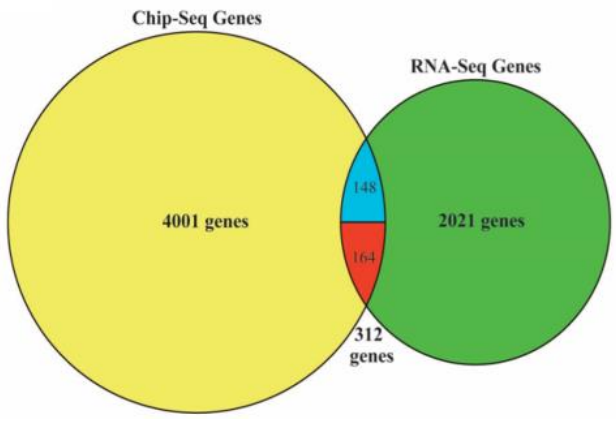

$\mathrm{F}$

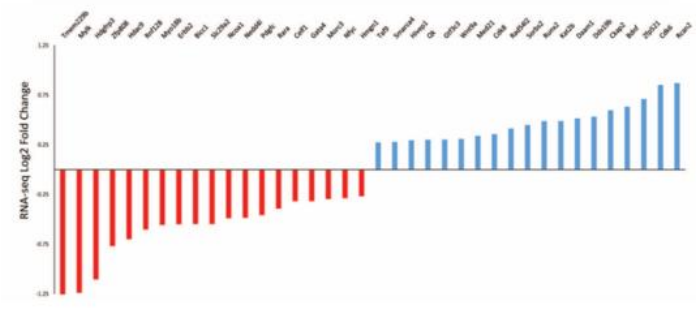


Figure 4.

A

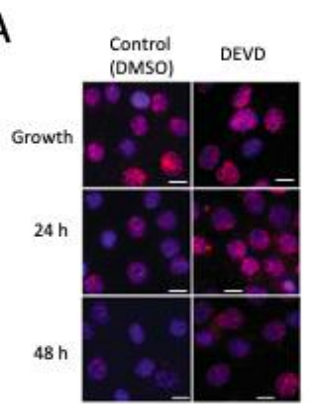

D
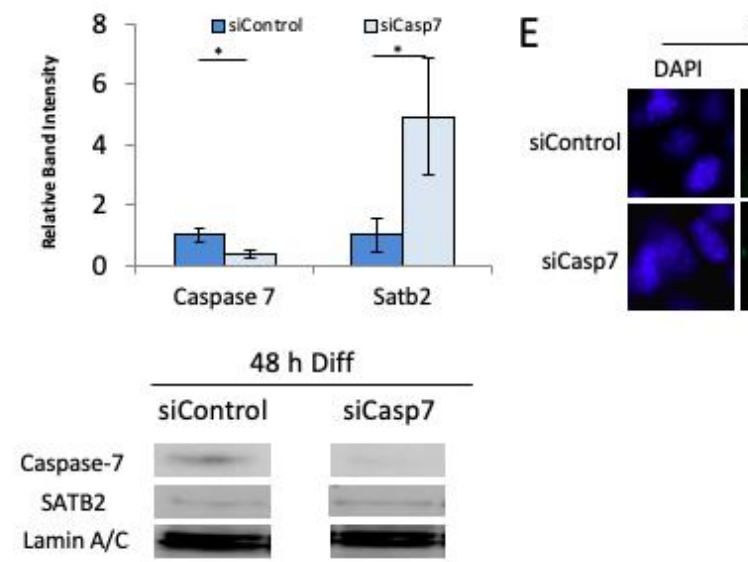

F

Differentiation Time Course
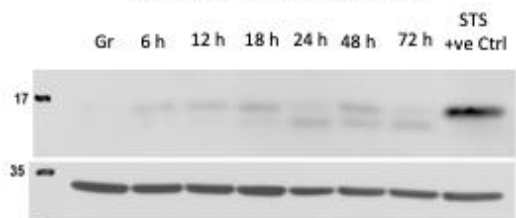

Active

caspase 7

GAPDH
C

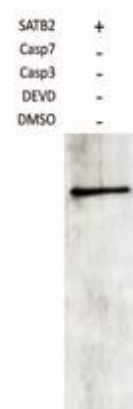

$48 \mathrm{~h}$ Diff

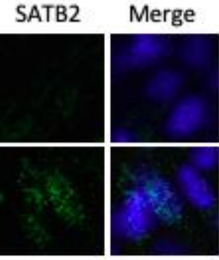

Growth

$24 \mathrm{~h}$

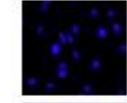

$48 \mathrm{~h}$

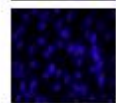

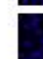

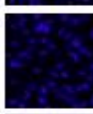

$96 \mathrm{~h}$

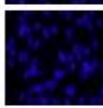

G
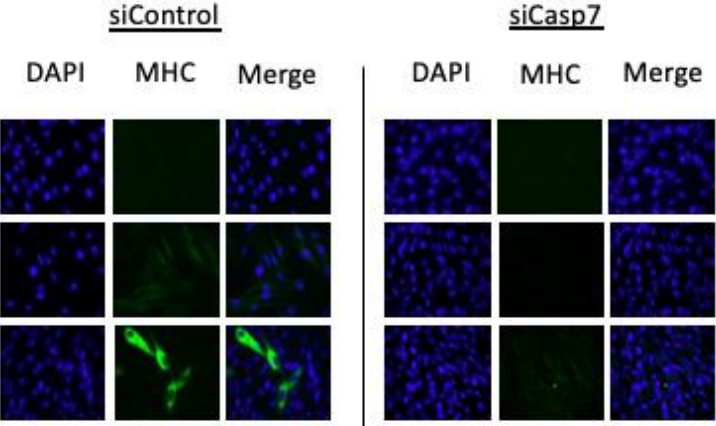

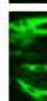
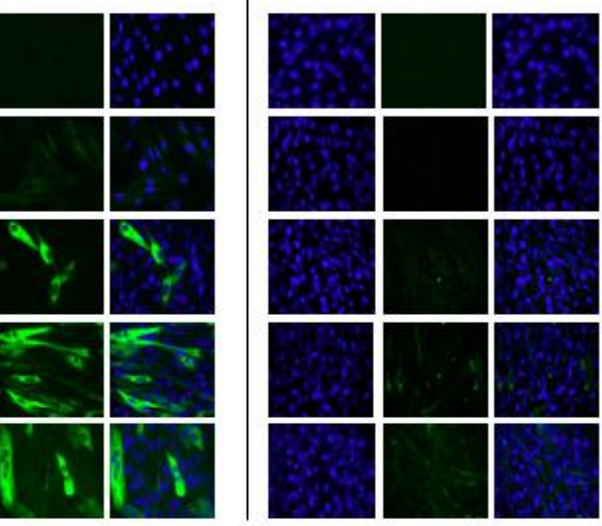
Supplemental Information

Figure 1.

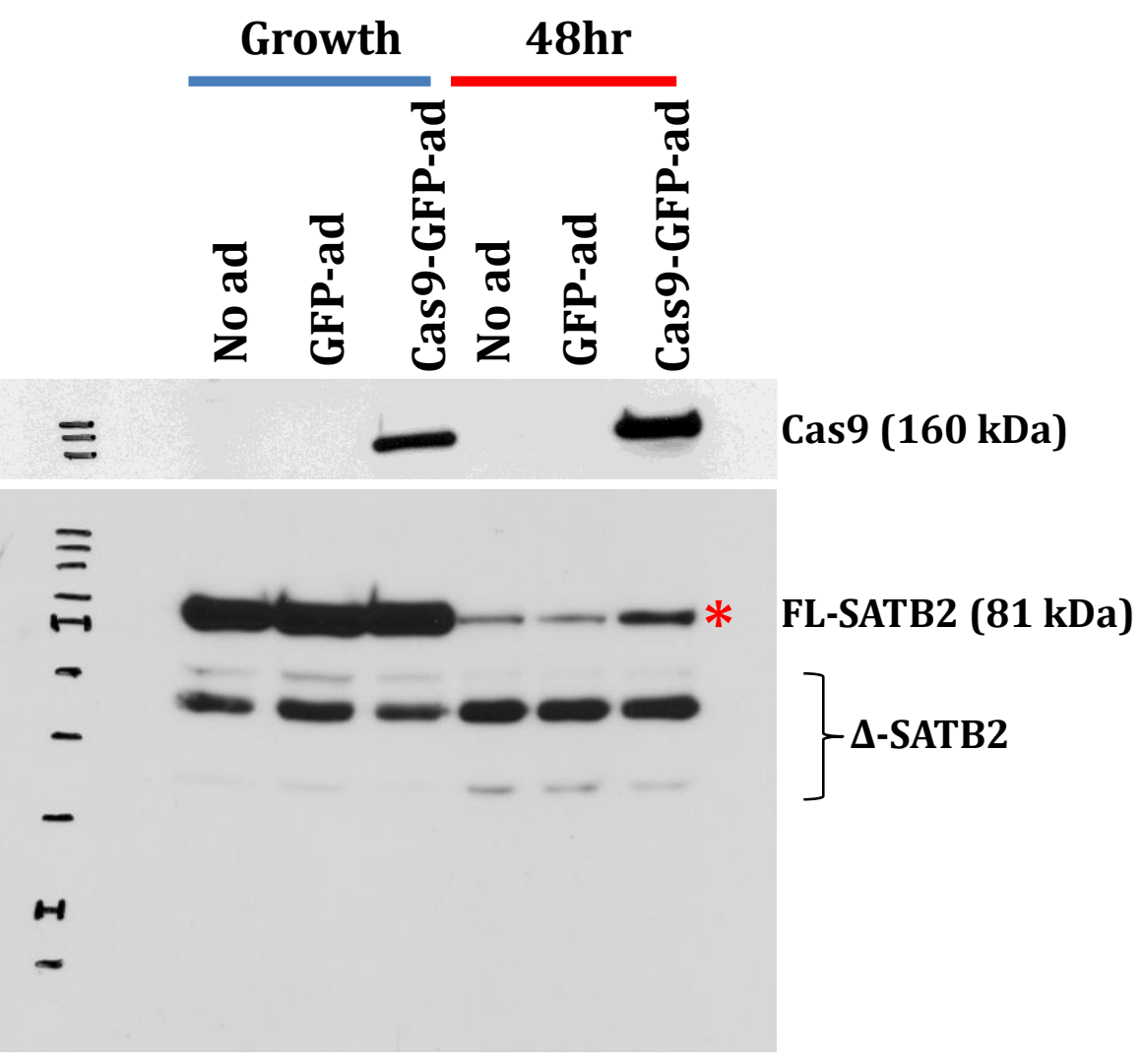


Figure 2

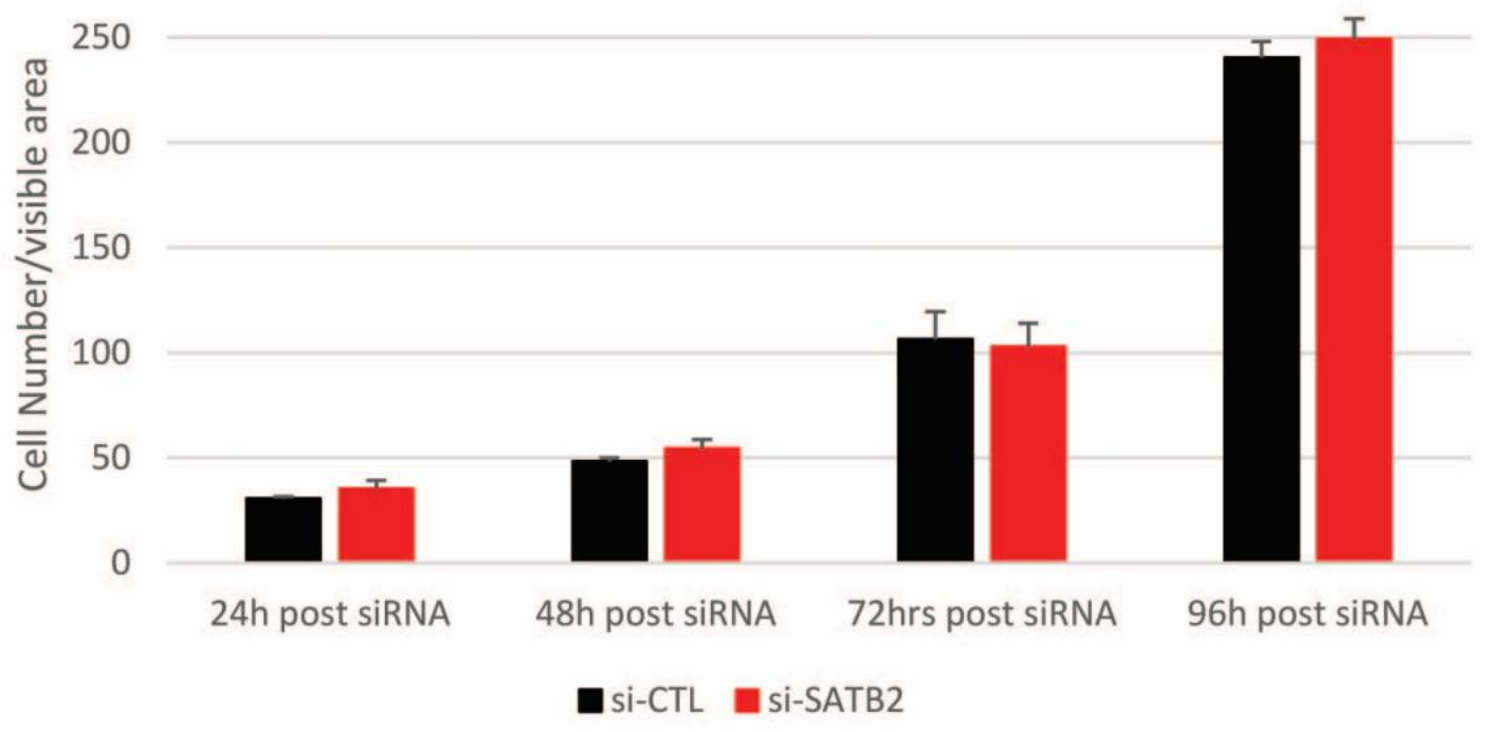


Figure 3

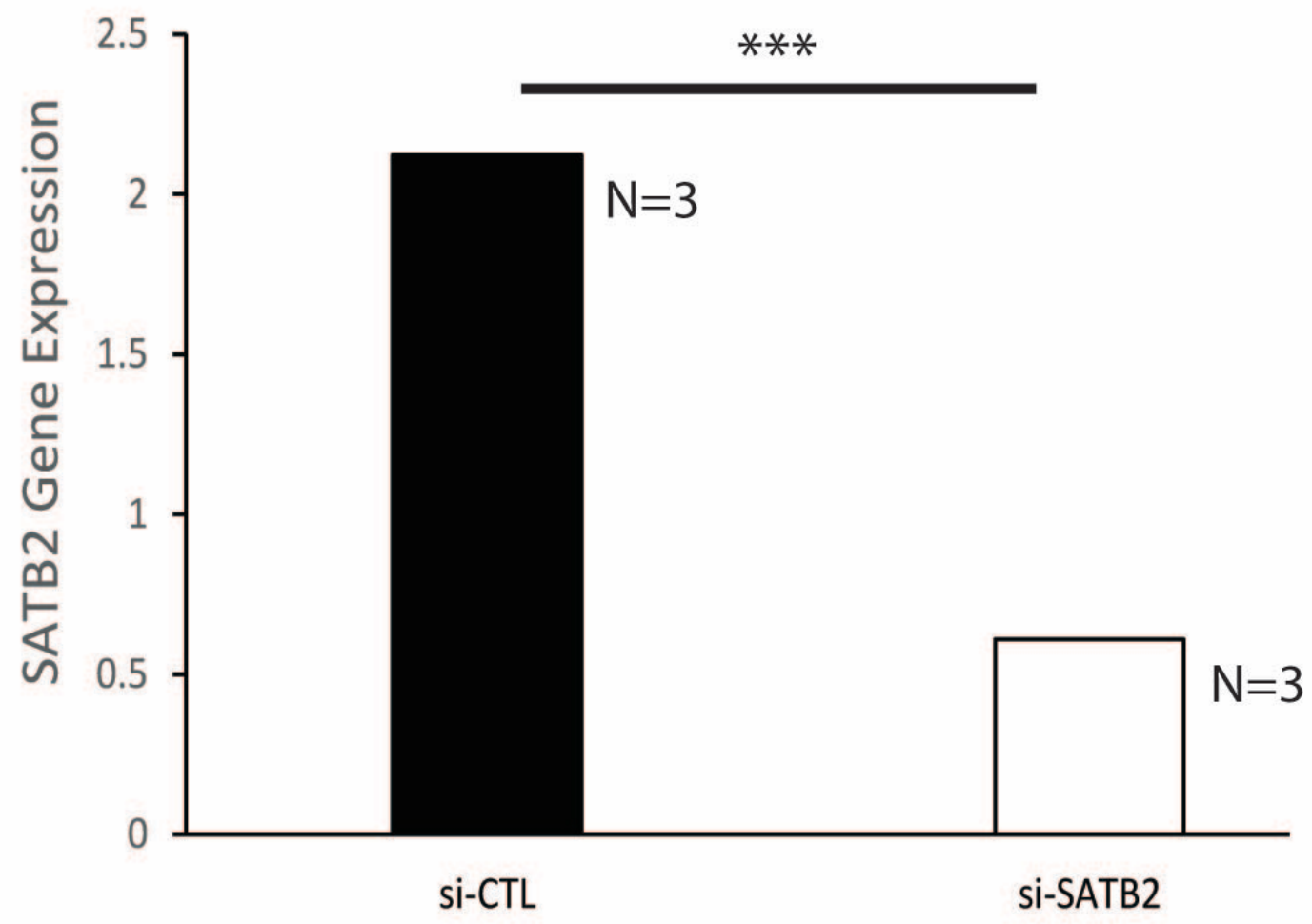


bioRxiv preprint doi: https://doi.org/10.1101/2019.12.19.883579; this version posted December 20, 2019. The copyright holder for this preprint (which was not certified by peer review) is the author/funder. All rights reserved. No reuse allowed without permission.

Figure 4.

A

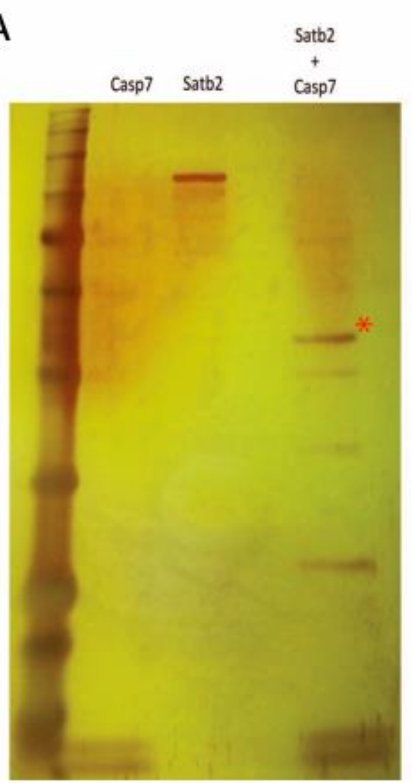

\section{B}

\begin{tabular}{|c|c|c|c|c|c|c|c|c|}
\hline Start - tad & Oboerwed & $\operatorname{It}(\operatorname{expt})$ & It (exle) & $p p e x$ & N Scote & Expoet & Rank & 0 Peptide \\
\hline $67 \cdot 66$ & 1069.5300 & 2137.0455 & 2137.0361 & 1.4: 0 & $\pi$ & $1.16 \cdot 06$ & 1 & 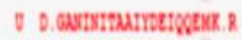 \\
\hline $678-636$ & 1069.5302 & 2137.0458 & 213 & 4.520 & 41 & 0.037 & 1 & o D. cartstzu: \\
\hline$m \cdot 6 n$ & 0575 & 17.1809 & 2279.423 & 3.6.1 & $\$ 1$ & 0.0027 & 1 & 0 D. garstrutrotswos. A \\
\hline $67 \cdot 67$ & 1139. .453 & 17.156! & & 6.011 & 4 & 0.00016 & 1 & $\log .1$ \\
\hline $698-497$ & & 93.16 & & 3.451 & It & 0.58 & $!$ & (1) 0.0258 \\
\hline $67-69$ & 765.3498 & 2293.2675 & 2293.1372 & 4.61 & 15 & 0.59 & 1 & 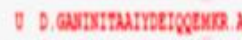 \\
\hline $2 \cdot 497$ & 6520 & 1939.934 & & 1.451 & 1 & 1.6 & 3 & 0 t.mumertogens $\mathrm{A}$. \\
\hline $498-507$ & 531.6209 & 1061.6273 & 1061.6233 & 3.761 & 1 & 0.23 & 1 & 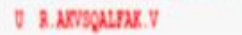 \\
\hline
\end{tabular}


bioRxiv preprint doi: https://doi.org/10.1101/2019.12.19.883579; this version posted December 20, 2019. The copyright holder for this preprint (which was not certified by peer review) is the author/funder. All rights reserved. No reuse allowed without permission.

\section{Figure 5.}

\begin{tabular}{|c|c|c|c|c|c|}
\hline MERRSESPCL & RDSPDRRSGS & PDVKGPPPVK & ARLEQNGSP & MGARGRPNGA & \\
\hline PVFCVVEQLD & GSLEYDNREE & HAEFVLVRKD & VLFSQLVETA & LLALGYSHSS & AAQAQG I IKL \\
\hline GRWNPLPLSY & VTDAPDATVA & DMLQDVYHVV & TLKIQ̋LQSCS & KLEDLPAEQW & NHÄTV̈RNALK \\
\hline ELLKEMNQST & LAKECPLSQS & MISSIVNSTY & YANVSATKCQ & EFGRWYKKYK & KIKVERVER \\
\hline NLSDYCVLGQ & RPMHLPNMNQ & LASLGKTNEQ & SPHSQIHHST & PIRNQVPALQ & LLS \\
\hline QLSPQLVRQQ & IAMAHL INQQ & IAVSRLLAHQ & HPQA INQQFL & NHPPI PRAVK & PEPTNSSVEV \\
\hline SPDIYQQVRD & ELKRASVSQA & VFARVAFNRT & QGLLSE I LRK & EEDPRTASQS & LLVNLRAMQN \\
\hline FLNLPEVERD & RIYQDERERS & MNPNVSMVSS & ÄSSSPSSSRT & PQAKTSTPTT & DLPIKVDGAN \\
\hline INITAAIYDE & IQQEMKRAKV & SQALFAKVAA & NKSQGWLCEL & LRWKENPSPE & NRTLWENLC \\
\hline IRRELNLPQH & ERDVIYEEES & RHHHSERMQH & VVQIPPEPVQ & VLHRQQSQPA & KESSPPREE \\
\hline PPPPPPTEDS & CAKKPRSRTK & ISLEALGILQ & SEIHDVGLYP & & QLDLPKHTI \\
\hline & & GSAVDVAFYK & DEELLTESEE & NDS & EAE \\
\hline
\end{tabular}


Figure 6.

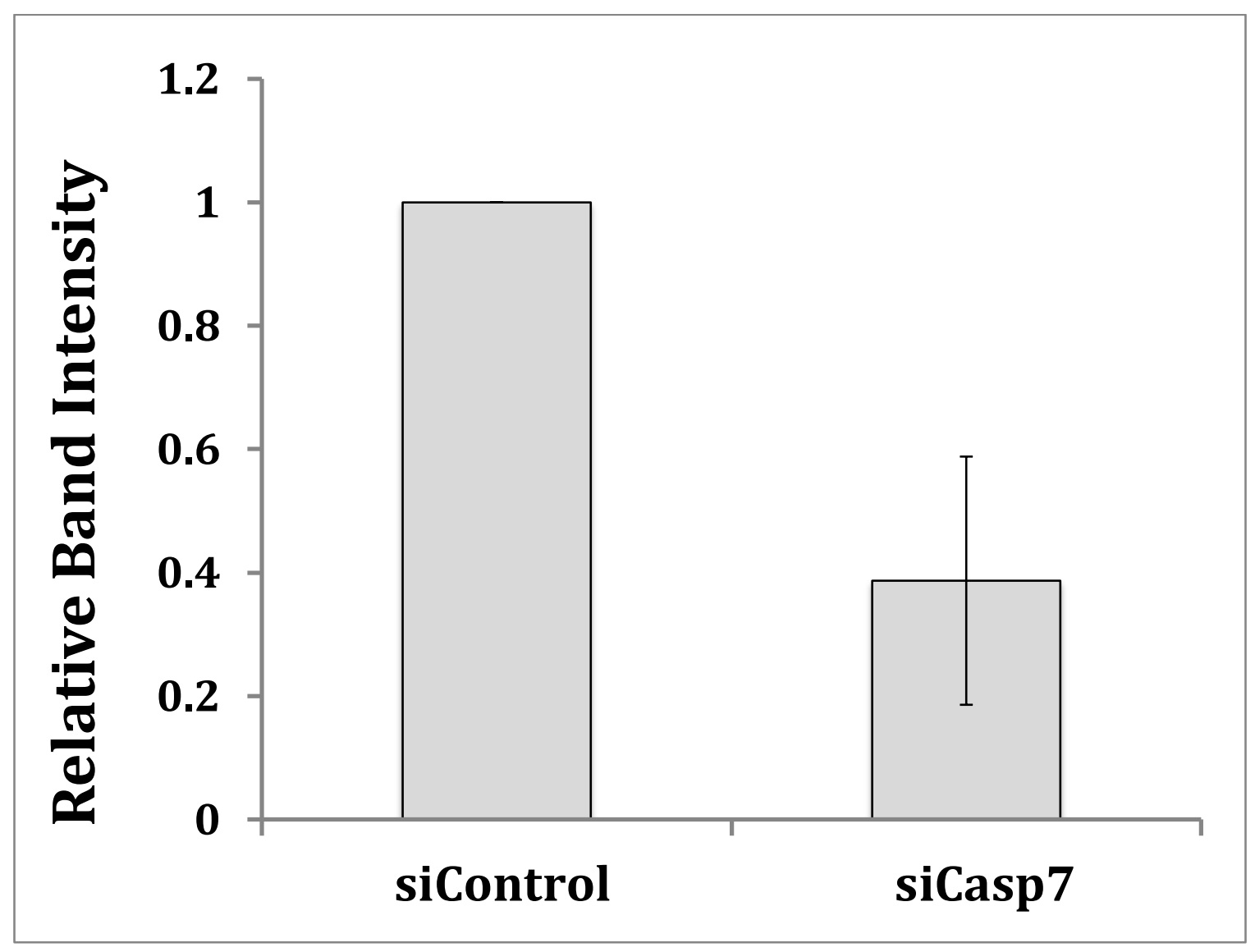


Figure 7.

A

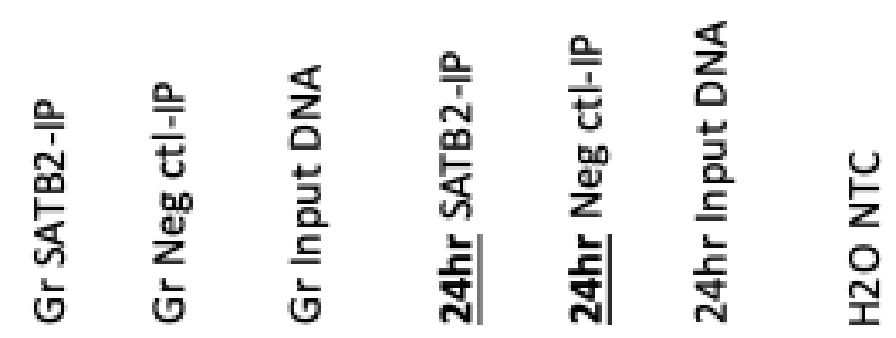

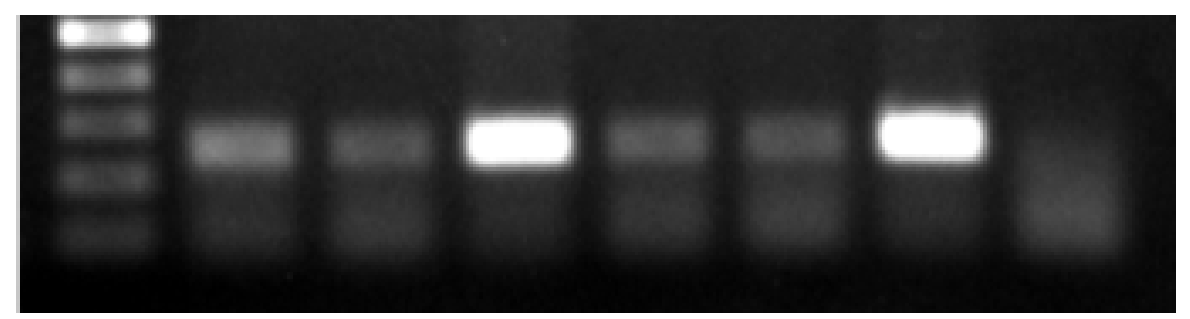

B

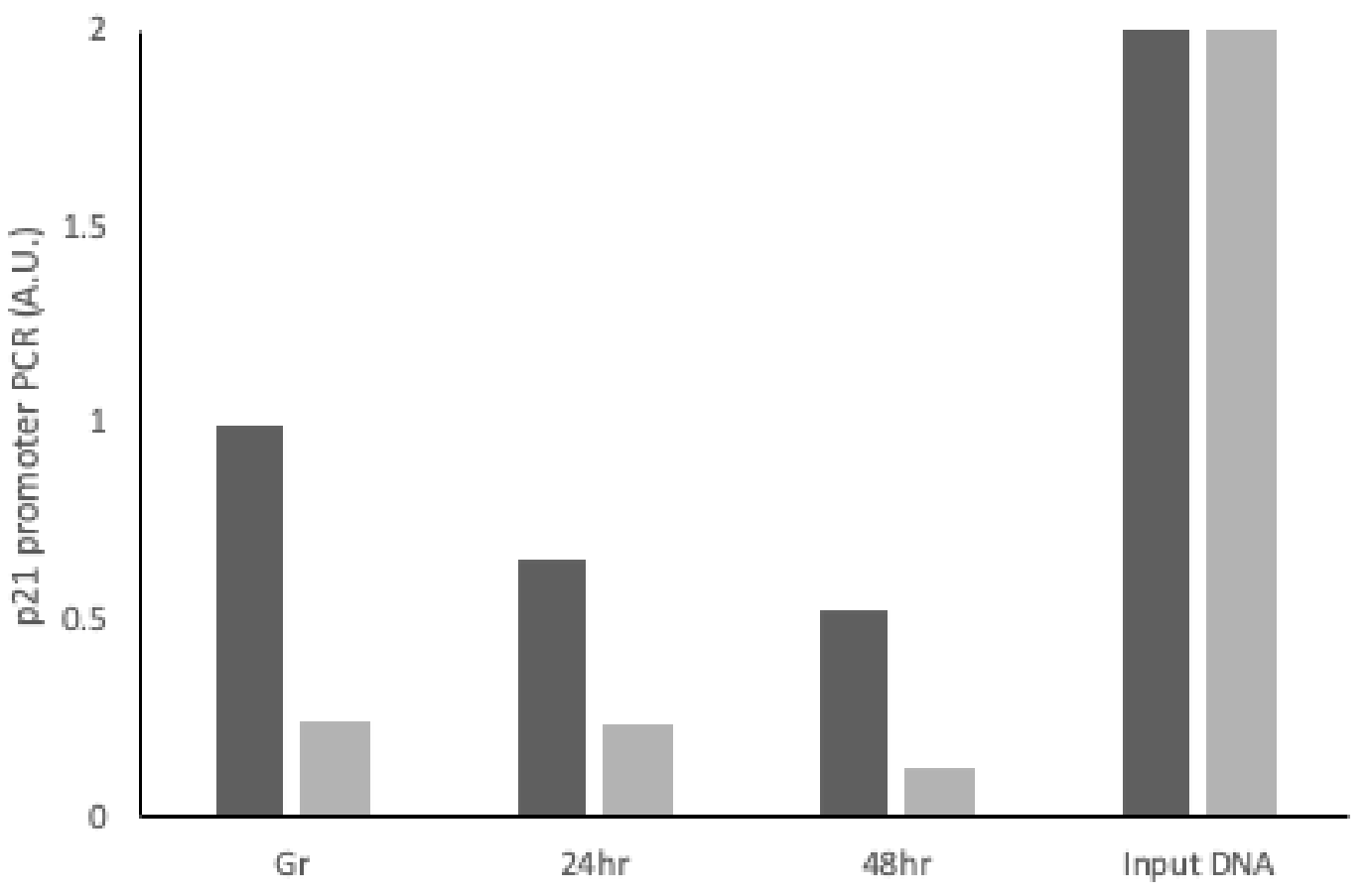

Differentiation Time course $\quad$ SATB2-IP $\quad$ IgG-IP 
bioRxiv preprint doi: https://doi.org/10.1101/2019.12.19.883579; this version posted December 20, 2019. The copyright holder for this preprint (which was not certified by peer review) is the author/funder. All rights reserved. No reuse allowed without permission.

\section{Table 1}

\begin{tabular}{|c|c|c|c|c|c|c|c|c|c|c|}
\hline Name & Raw P-Value & FDR Q-Val & Fold Enrichment & Observed Region Hits $\mathrm{R}$ & Region Set Coverage & FDR Q-Val & Fold Enrichment & Observed Gene Hits & Total Genes & Gene Set Coverage \\
\hline chromatin modification & 1.60E-16 & $3.75 \mathrm{E}-14$ & \begin{tabular}{r|}
1.5418 \\
\end{tabular} & 397 & $\begin{array}{r}4.41 \% \\
\end{array}$ & 9.41E-06 & 1.3246 & 202 & 397 & \begin{tabular}{|r|}
$2.40 \%$ \\
\end{tabular} \\
\hline mitosis & $3.46 \mathrm{E}-15$ & $6.71 \mathrm{E}-13$ & 1.6686 & 268 & $2.97 \%$ & $5.42 E-04$ & 1.3154 & 144 & 285 & $1.71 \%$ \\
\hline cell division & $4.58 \mathrm{E}-15$ & $8.38 E-13$ & 1.5102 & 392 & $4.35 \%$ & $2.97 E-08$ & 1.3872 & 219 & 411 & $2.60 \%$ \\
\hline organelle fission & 4.74E-14 & $7.23 E-12$ & 1.6069 & 282 & $3.13 \%$ & $5.81 E-04$ & 1.3017 & 154 & 308 & $1.83 \%$ \\
\hline RNA splicing & $8.40 \mathrm{E}-11$ & $6.87 E-09$ & 1.6012 & 212 & $2.35 \%$ & $3.86 E-03$ & 1.2867 & 129 & 261 & $1.53 \%$ \\
\hline chromatin remodeling & $2.08 \mathrm{E}-09$ & $1.40 E-07$ & 1.8943 & 104 & $1.15 \%$ & $6.87 E-05$ & 1.7118 & 48 & 73 & $0.57 \%$ \\
\hline negative regulation of chromosome organization & $2.41 \mathrm{E}-09$ & $1.57 E-07$ & 2.4968 & 55 & $0.61 \%$ & $3.82 E-02$ & 1.6021 & 24 & 39 & $0.29 \%$ \\
\hline regulation of chromatin organization & $5.28 \mathrm{E}-08$ & $2.66 \mathrm{E}-06$ & 1.7836 & 102 & $1.13 \%$ & $4.59 \mathrm{E}-02$ & 1.3732 & 48 & 91 & $0.57 \%$ \\
\hline regulation of chromosome organization & $5.91 \mathrm{E}-08$ & $2.96 E-06$ & 1.6378 & 135 & $1.50 \%$ & $3.76 E-03$ & 1.4341 & 65 & 118 & $0.77 \%$ \\
\hline maintenance of location & $2.60 \mathrm{E}-07$ & 1.18E-05 & 1.722 & 102 & $1.13 \%$ & $9.61 \mathrm{E}-03$ & 1.4293 & 56 & 102 & $0.67 \%$ \\
\hline maintenance of location in cell & 4.07E-07 & $1.80 E-05$ & 1.8656 & 77 & $0.85 \%$ & $8.47 E-03$ & 1.5072 & 44 & 76 & $0.52 \%$ \\
\hline negative regulation of gene expression, epigenetic & $5.14 \mathrm{E}-07$ & $2.23 E-05$ & 2.6368 & 35 & $0.39 \%$ & $1.08 E-02$ & 1.9242 & 17 & 23 & $0.20 \%$ \\
\hline maintenance of protein location in cell & $5.50 \mathrm{E}-07$ & $2.36 E-05$ & 1.9241 & 69 & $0.77 \%$ & $1.35 E-02$ & 1.5154 & 39 & 67 & $0.46 \%$ \\
\hline blastocyst formation & $9.09 \mathrm{E}-07$ & $3.71 E-05$ & 2.1548 & 50 & $0.55 \%$ & $3.82 E-02$ & 1.6567 & 21 & 33 & $0.25 \%$ \\
\hline chromatin silencing & $9.82 \mathrm{E}-07$ & $3.97 E-05$ & 2.8006 & 30 & $0.33 \%$ & $2.84 E-02$ & 1.9183 & 14 & 19 & $0.17 \%$ \\
\hline ATP-dependent chromatin remodeling & $1.08 E-06$ & 4.34E-05 & 2.682 & 32 & $0.36 \%$ & $2.46 E-02$ & 1.9908 & 13 & 17 & $0.15 \%$ \\
\hline maintenance of protein location & $1.16 \mathrm{E}-06$ & $4.62 E-05$ & 1.7497 & 86 & $0.95 \%$ & $7.38 \mathrm{E}-03$ & 1.4876 & 48 & 84 & $0.57 \%$ \\
\hline maintenance of protein localization in organelle & $1.95 \mathrm{E}-06$ & $7.40 E-05$ & 3.5622 & 20 & $0.22 \%$ & $2.46 E-02$ & 1.9908 & 13 & 17 & $0.15 \%$ \\
\hline response to interleukin-1 & $6.38 \mathrm{E}-06$ & 2.19E-04 & 1.6823 & 84 & $0.93 \%$ & 1.04E-02 & 1.562 & 36 & 60 & $0.43 \%$ \\
\hline regulation of proteasomal protein catabolic process & $8.52 \mathrm{E}-06$ & $2.82 E-04$ & 1.6322 & 91 & $1.01 \%$ & $3.82 \mathrm{E}-02$ & 1.42 & 42 & 77 & $0.50 \%$ \\
\hline trophectodermal cell differentiation & $1.27 \mathrm{E}-05$ & 4.03E-04 & 2.1595 & 39 & $0.43 \%$ & $1.08 E-02$ & 1.9242 & 17 & 23 & $0.20 \%$ \\
\hline CDP-choline pathway & $1.40 \mathrm{E}-05$ & $4.41 E-04$ & 4.7449 & 12 & $0.13 \%$ & $4.11 E-02$ & 2.6034 & 6 & 6 & $0.07 \%$ \\
\hline RNA splicing, via transesterification reactions & $2.87 \mathrm{E}-05$ & 8.64E-04 & 1.7009 & 69 & $0.77 \%$ & $2.00 E-03$ & 1.6172 & 41 & 66 & $0.49 \%$ \\
\hline mRNA splicing, via spliceosome & $3.53 \mathrm{E}-05$ & $1.04 E-03$ & 1.6964 & 68 & $0.75 \%$ & $1.99 \mathrm{E}-03$ & 1.6271 & 40 & 64 & $0.48 \%$ \\
\hline labyrinthine layer development & $7.38 \mathrm{E}-05$ & $1.99 \mathrm{E}-03$ & 1.6604 & 67 & $0.74 \%$ & $4.62 \mathrm{E}-03$ & 1.6521 & 33 & 52 & $0.39 \%$ \\
\hline
\end{tabular}




\section{Table 2}

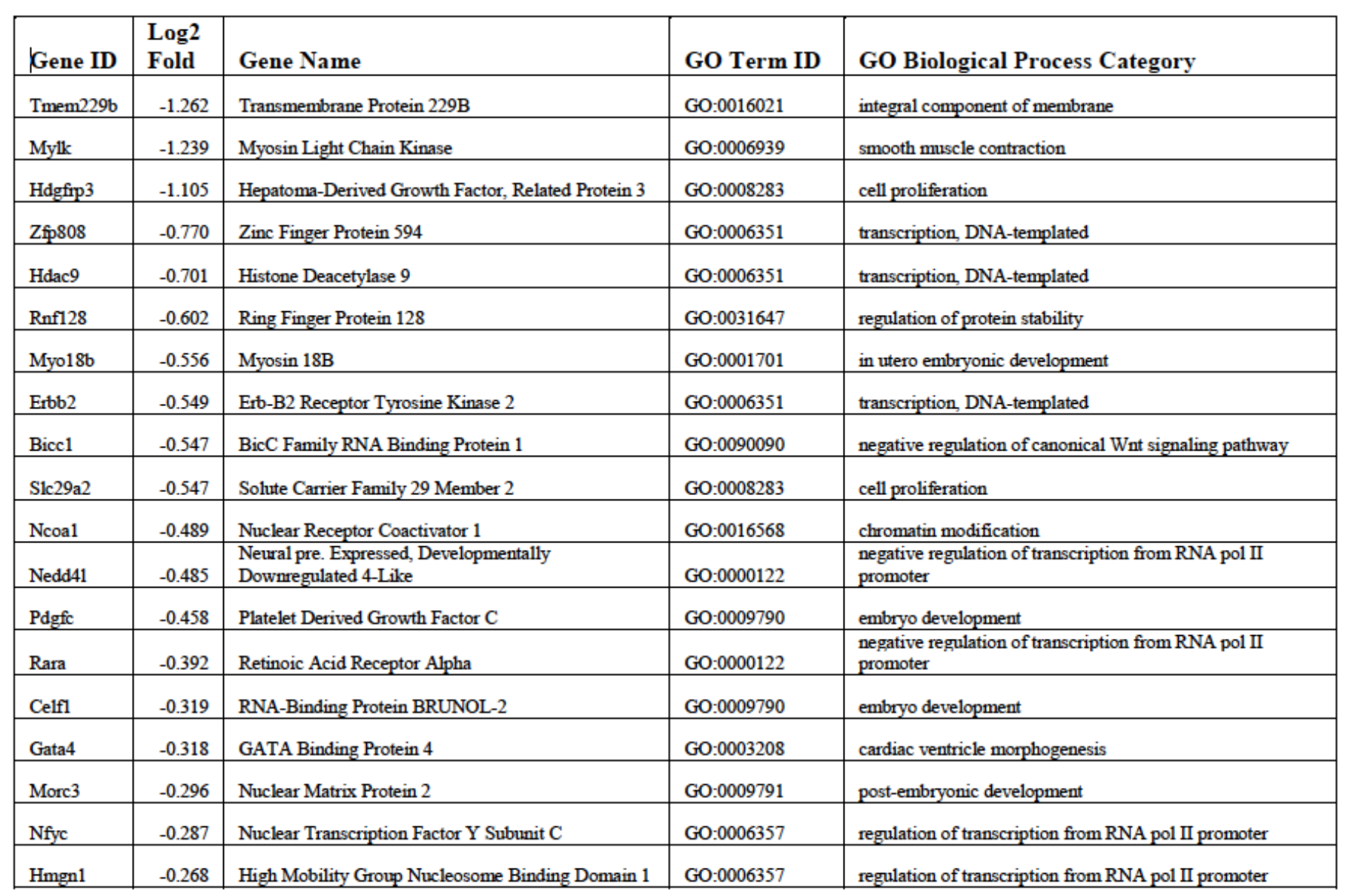




\section{Table 3}

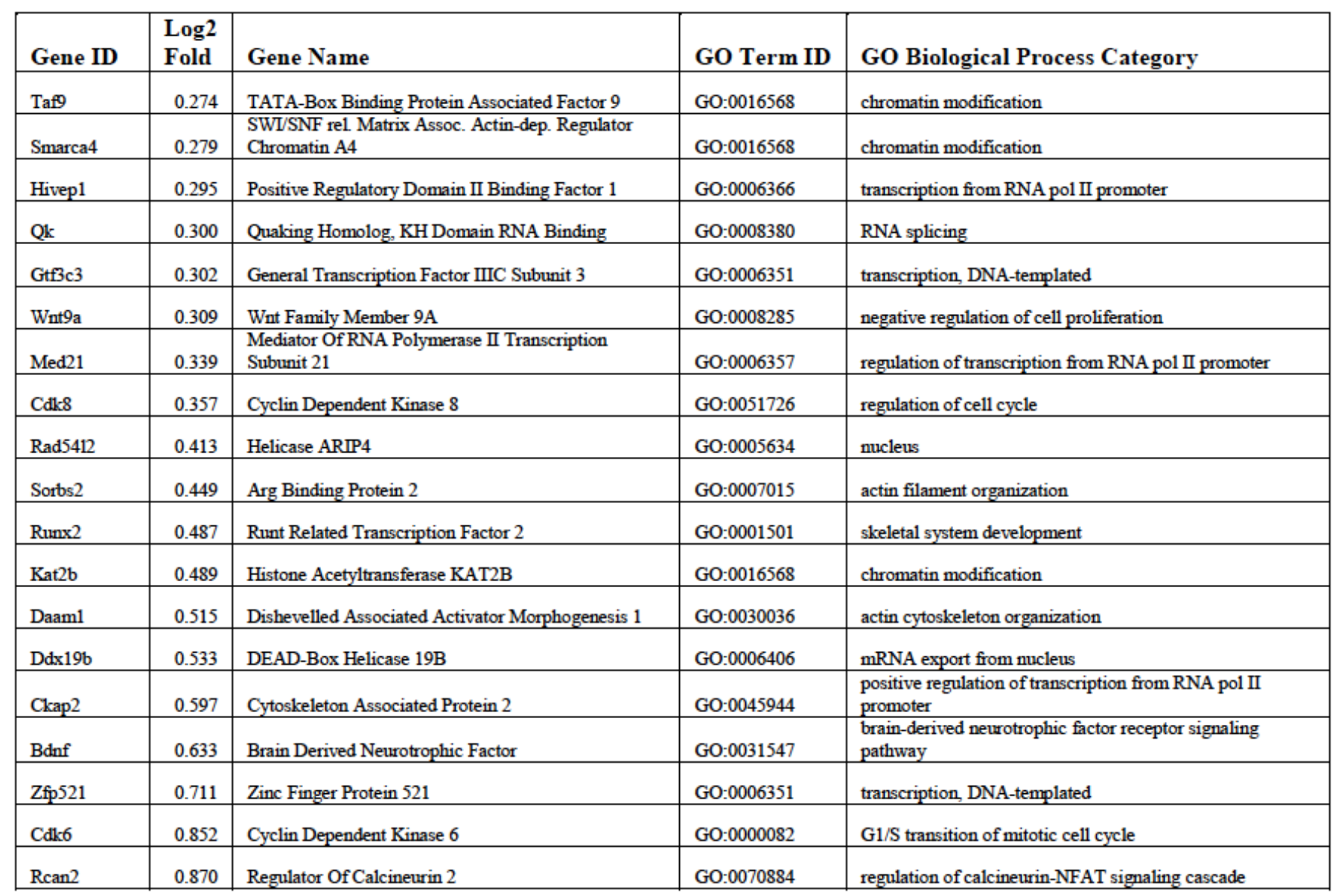




\section{References}

Albini, S., Toto, P.C., Dall'Agnese, A., Malecova, B., Cenciarelli, C., Felsani, A., Caruso, M., Bultman, S.J., and Puri, P.L. (2015). Brahma is required for cell cycle arrestand late muscle gene expression during skeletal myogenesis. EMBO Rep. 16, 10371050.

Al-Khalaf, M.H., Blake, L.E., Larsen, B.D., Bell, R.A.V., Brunette, S., Parks, R.J., Rudnicki, M.A., McKinnon, P.J., Dilworth, F.J. and Megeney, L.A. (2016). Temporal activation of XRCC1-mediated DNA repair is essential for muscle differentiation. Cell Discov. 12, 15041.

Arope, S., Harraghy, N., Pjanic, M., and Mermod, N. (2013). Molecular characterization of a human matrix attachment region epigenetic regulator. PLoS One 8, e79262.

Asanoma, K., Kubota K., Chakraborty, D., Renaud, S.J., Wake, N., Fukushima, K., Soares M.J. and Rumi, M.A. (2012). SATB homeobox proteins regulate trophoblast stem cell renewal and differentiation. J. Biol. Chem. 287, 2257-2268.

Bell, R.A.V. and Megeney, L.A. (2017). Evolution of caspase-mediated cell death and differentiation: twins separated at birth. Cell Death Diff 24, 1359-1368.

Bengani, H., Handley, M., Alvi, M., Ibitoye, R., Lees, M., Lynch, S.A., Lam, W.,. Fannemel, M., Nordgren, A., Malmgren, H., Kvarnung, M., Mehta, S., McKee, S., 
Whiteford, M., Stewart, F., Connell, F., Clayton-Smith, J., Mansour, S., Mohammed, S., Fryer, A., Morton, J., UK10K Consortium, Grozeva, D., Asam, T., Moore, D., Sifrim, A., McRae, J., Hurles, M.E., Firth, H.V., Raymond, F.L., Kini, U., Nelláker, C., Ddd Study, and FitzPatrick, D.R. (2017) Clinical and molecular consequences of disease-associated de novo mutations in SATB2. Nature 19, 900-908.

Britanova, O., Akopov, S., Lukyanov, S., Gruss, P. and Tarabykin, V. (2005). Novel transcription factor SATB2 interacts with matrix attachment region DNA elements in a tissue-specific manner and demonstrates cell-type-dependent expression in the developing mouse CNS. Eur J Neuro. 21, 658-668.

Buas, M.F. and Kadesch, T. (2010). Regulation of skeletal myogenesis by Notch. Exp. Cell Res. 316, 3028-3033.

Bushey, A.M., Dorman, E.R., and Corces, V.G. (2008). Chromatin insulators: regulatory mechanisms and epigenetic inheritance. Mol. Cell 32, 1-9.

Chen, T. and Dent, S.Y.R. (2014). Chromatin modifiers: regulators of cellular differentiation. Nat. Rev. Genet. 15, 93-106.

de la Serna, I.L., Ohkawa, Y. and Imbalzano, A.N. (2006). Chromatin remodeling in mammalian differentiation: lessons from ATP-dependent remodelers. Nat. Rev. Genet. 7, 461-473. 
Dick, S.A., Chang, N.C., Dumont, N.A., Bell, R.A.V., Putinski, C., Kawabe, Y., Litchfield, D.W., Rudnicki, M.A. and Megeney, L.A. (2015). Caspase 3 cleavage of Pax7 inhibits self-renewal of satellite cells. Proc. Natl. Acad. Sci. USA 112, E5246-E5252.

Dixon, J.R., Jung, I., Selvaraj, S., Shen, Y., Antosiewicz-Bourget, J.E., Lee, A.Y., Ye, Z., Kim, A., Rajagopal, N., Xie, W. et al. (2015). Chromatin architechture reorganization during stem cell differentiation. Nature 518, 331-336.

Dobreva G., Chahrour, M., Dautzenberg, M., Chirivella L., Kanzler, B., Fariñas, I., Karsenty, G. and Grosschedl, R. (2006). SATB2 is a multifunctional determinant of craniofacial patterning and osteoblast differentiation. Cell 125, 971-986.

Dong, W., Zhang, P., Fu, Y., Ge, J., Cheng, J., Yuan, H., and Jiang, H. (2015). Roles of SATB2 in site-specific stemness, autophagy and senescence of bone marrow mesenchymal stem cells. J. Cell. Physiol. 230, 680-690.

Doynova, M.D., Markworth, J.F., Cameron-Smith, D., Vickers, M.H., and O’Sullivan, J.M. (2017). Linkages between changes in the 3D organization of the genome and transcription during myotube differentiation in vitro. Skelet. Muscle 7, 5. 
Dudek, A.H., Pfaff, F., Bolte, H., Waguia Kontchou, C., and Schwemmie, M. (2018).

Partial inactivation of chromatin remodelers SMARCA2 and SMARCA4 in virusinfected cells by caspase-mediated cleavage. J Virol. 92

Fernando, P., Kelly, J.F., Balazsi, K., Slack, R.S. and Megeney, L.A. (2002). Caspase 3 activity is required for skeletal muscle differentiation. Proc. Natl. Acad. Sci. USA 99, 11025-11030.

Fisher, C.L. and Fisher, A.G. (2011). Chromatin states in pluripotent, differentiated, and reprogrammed cells. Curr. Opin. Genet. Dev. 21, 140-146.

Forcales, S.V., Albini, S., Giordani, L., Malecova, B., Cignolo, L., Chemov, A., Coultinho, P., Saccone, V., Consalvi, S., Williams, R., Wang, K., Wu, Z., Baranovskaya, S., Miller, A., Dilworth, F.J., and Puri, P.L. (2012). Signal-dependent incorporation of MyoD-BAF60c into Brg1-based SWI/SNF chromatin-remobelling complex. EMBO J. $31,301-316$.

Galande, S., Dickinson, L.A., Milan, I.S., Sikorska, M., and Kohwi-Shigematsu, T. (2001). SATB1 cleavage by caspase 6 disrupts PDZ domain-mediated dimerization, causing detachment from chromatin early in T-cell apoptosis. Mol Cell Biol. 21, 55915604. 
Gómez-Díaz, E. and Corces, V.G. (2014). Architectural proteins: regulators of 3D genome organization in cell fate. Trends Cell Biol. 24, 703-711.

Gotzmann, J., Vicek, S., and Foisner, R. (2000). Caspase-mediated cleavage of the chromosome-binding domain of lamina-associated polypeptide $2 \alpha$. J. Cell Sci. 113, 37693780.

Griffin, C.T., Brennan, J., and Magnuson, T. (2008). The chromatin-remodeling enzyme BRG1 plays an essential role in primitive erythropoiesis and vascular development. Development 135, 493-500.

Han, H.J., Russo, J., Kohwi, Y., and Kohwi-Shigematsu, T. (2008). SATB1 reprogrammes gene expression to promote breast tumour growth and metastasis. Nature 452, 187-193.

Hawkins, S.M., Kohwi-Shigematsu, T., and Skalnik, D.G. (2001). The matrix attachment region-binding protein SATB1 interacts with multiple elements within the gp91phox promoter and is down-regulated during myeloid differentiation. J Biol Chem. 276, 4447244480.

Hota, S.K. and Bruneau, B.G. (2016). ATP-dependent chromatin remodeling during mammalian development. Development 143, 2882-2897. 
Jaitner, C., Reddy, C., Abentung, A., Whittle, N., Rieder, D., Delekate, A., Korte, M., Jain, G., Fischer, A., Sananbenesi, F., Cera, I., Singewald, N., Dechant, G., and Apostolova, G. (2016). Satb2 determines miRNA expression and long-term memory in the adult central nervous system. eLife 5, e17361.

Kamada, S., Kikkawa, U., Tsujimoto, Y. and Hunter T. (2005). Nuclear translocation of caspase- 3 is dependent on its proteolytic activation and recognition of a substrate-like protein(s). J. Biol. Chem. 280, 857-860.

Keenen, B. and de la Serna, I.L. (2008). Chromatin remodeling in embryonic stem cells: Regulating the balance between pluripotency and differentiation. J. Cell. Physiol. 219, 17.

Lapierre, M., Linares, A., Dalvai, M., Duraffourd, C., Bonnet, S., Boulahtouf, A., Rodriguez, C., Jalaguier, S., Assou, S., Orsetti, B., Balaguer, P., Maudelonde, T., Blache, P., Bystricky, K., Boulle, N., and Cavaillès, V. (2016). Histone deacetylase 9 regulates breast cancer cell proliferation and the response to histone deacetylase inhibitors. Oncotarget 7, 19693-19708.

Larsen, B.D., Rampalli, S., Burns, L.E., Brunette, S., Dilworth, F.J. and Megeney, L.A. (2010). Caspase 3/caspase-activated DNase promote cell differentiation by inducing DNA strand breaks. Proc. Natl. Acad. Sci. USA 107, 4230-4235. 
Larsen, B.D. and Sørensen, C.S. (2017). The caspase-activated DNase: apoptosis and beyond. FEBS J. 284, 1160-1170.

Lee, Y.B., Colley, S., Norman, M., Biamonti, G., and Uney, J.B. (2007). SAFB redistribution marks steps of the apoptotic process. Exp. Cell Res. 313, 3914-3923.

Lee, Y., Wang, C., Huang, S.K., Wu, W., Huang, C., Li, C., Chan, T., Liang, P., Hsing, C. and Li, C. (2016). Downregulation of RNF128 predicts progression and poor prognosis in patients with urothelial carcinoma of the upper tract and urinary bladder. $\mathrm{J}$. Cancer 7, 2187-2196.

Leone, D.P., Heavner, W.E., Ferenczi, E.A., Dobreva, G., Huguendard, J.R., Grosschedl, R. and McConnell, S.K. (2015). Satb2 regulates the differentiation of both callosal and subcerebral projection neurons in the developing cerebral cortex. Cereb. Cortex 25, 34063419.

Matalova, E., Lesot, H., Svandova, E., Vanden Berghe, T., Sharpe, P.T., Healy, C., Vandenabeele, P., and Tucker, A.S. (2013). Casepase-7 participates in differentiation of cells forming dental hard tissues. Dev Growth Differ. 55, 615-621.

McLean, C.Y., Bristor, D., Hiller, M., Clarke, S.L., Schaar, B.T., Lowe, C.B., Wenger, A.M. and Bejerano, G. (2010). GREAT improves functional interpretation of cisregulatory regions. Nature $28,495-501$. 
Müller, C. and Leutz, A. (2001). Chromatin remodeling in development and differentiation. Curr. Opin. Genet. Dev. 11, 167-174.

Murray, T.V.A., McMahon, J.M., Howley, B.A., Stanley, A., Ritter, T., Mohr, A., Zwacka, R., and Fearnhead, H.O. (2008). A non-apoptotic role for caspase-9 in muscle differentiation. J. Cell Sci. 121, 3786-3793.

Nishijo, K., Hosoyama, T., Bjornson, C.R.R., Schaffer, B.S., Prajapati, S.I., Bahadur, A.N., Hansen, M.S., Blandford, M.C., McGleish, A.T., Rubin, B.P., Epstein, J.A., Rando, T.A., Capecchi, M.R., and Keller, C. (2009). Biomarker system for studying muscle, stem cells, and cancer in vivo. FASEB J. 23, 2681-2690.

Richter, J., Stanley, E.G., Ng, E.S., Elefanty, A.G., Traver, D., and Willert, K. (2018). WNT9A is a conserved regulator of hematopoietic stem and progenitor cell development. Genes 9, 66.

Robinson, D.C.L. and Dilworth, J.F. (2018). Epigenetic regulation of adult myogenesis. Curr. Top. Dev. Biol. 126, 235-284.

Savarese, F., Dávila A., Nechanitzky, R., De La Rosa-Velazquez, I., Pereira C.F., Engelke, R., Takahashi, K., Jenuwein, T., Kohwi-Shigematsu, T., Fisher, A.G., et al. 
(2009). Satb1 and Satb2 regulate embryonic stem cell differentiation and Nanog expression. Genes Dev. 23, 2625-2638.

Slaymaker, I.M., Gao, L., Zetsche, B., Scott, D.A., Yan, W.X., and Zhang, F. (2016). Rationally engineered Cas9 nucleases with improved specificity. Science 351, 84-88.

Svandova, E., Vesela, B., Tucker, A.S., and Matalova, E. (2018). Activation of proapoptotic caspases in non-apoptotic cells during odontogenesis and related osteogenesis. Front Physiol. 9, 174.

Sun, Y., Wang, T., Su, Y., Yin, Y., Xu, S., Ma, C., and Han, X. (2006). The behavior of SATB1, a MAR-binding protein, in response to apoptosis stimulation. Cell Biol Int. 30, 244-247.

Tanaka, S., Terada, K., and Nohno, T. (2011). Canonical Wnt signaling is involved in switching from cell proliferation to myogenic differentiation of mouse myoblast cells. J. Mol. Signal. 6, 12.

Trapnell, C., Hendrickson, D.G., Sauvageau, M., Goff, L., Rinn, J.L. and Pachter, L. (2013). Differential analysis of gene regulation at transcript resolution with RNA-seq. Nat. Biotech. 31, 46-53. 
Unsain, N. and Barker, P.A. (2015). New Views on the Misconstrued: Execuitoner caspases and their diverse non-apoptotic roles. Neuron 88, 461-474.

Wang, L., Li, W., Li, K., Guo, Y., Liu, D., Yao, Z., Lin, X., Li, S., Jiang, Z., Liu, Q., Jiang, Y., Zhang, X., Chen, L., Zhou, F., Ren, H., Lin, D., Zhang, D., Yeung, S.J., and Zhang, H. (2018). The oncogenic roles of nuclear receptor coactivator 1 in human esophageal carcinoma. Canc. Med. 7, 5205-5216.

Xia, L., Sun, C., Li, Q., Feng, F., Qiao, E., Jiang, L., Wu, B., and Ge, M. (2015). CELF1 is up-regulated in glioma and promotes glioma cell proliferation by suppression of CDKN1B. Int. J. Biol. Sci. 11, 1314-1324.

Xiao, Q., Qu, K., Wang, C., Kong, Y., Liu, C., Jiang, D., Saiyin, H., Jia, F., Ni, C., Chen, T., Zhang, Y., Zhang, P., Qin, W., Sun, Q., Wang, H., Yi, Q., Liu, J., Huang, H., and Yu, L. (2013). HDGF-related protein-3 is required for anchorage-independent survival and chemoresistance in hepatocellular carcinomas. Gut 62, 440-451.

Ye, Y., Li, M., Gu, L., Chen, X., Shi, J., Zhang, X., and Jiang, C. (2017) Chromatin remodeling during in vivo neural stem cells differentiating to neurons in early Drosophila embryos. Cell Death Diff. 24, 409-420.

Yu, Y., Chen, Y., Kim, B., Wang, H., Zhao, C., He, X., Liu, L., Liu, W., Wu, L.M.N., Mao, M., Chan, J.R., Wu, J., and Lu, Q.R. (2013). Olig2 targets chromatin remodelers to enhancers to initiate oligodendrocyte differentiation. Cell 152, 248-261. 
Zhivotovsky, B., Samali, A., Gahm, A. and Orrenius, S. (1999). Caspases: their intracellular localization and translocation during apoptosis. Cell Death Diff. 6, 644-651. 